\title{
Issues, Challenges, and Research Trends in Spectrum Management: A Comprehensive Overview and New Vision for Designing 6G Networks
}

\author{
Faizan Qamar ${ }^{1}{ }^{(0)}$, Maraj Uddin Ahmed Siddiqui $\left.{ }^{2}{ }^{(}\right)$, MHD Nour Hindia ${ }^{3}$, Rosilah Hassan ${ }^{4, *(B)}$ \\ and Quang Ngoc Nguyen ${ }^{5, *}$ (i) \\ 1 Faculty of Information Science and Technology, Universiti Kebangsaan Malaysia (UKM), Bangi, \\ Selangor 43600, Malaysia; faizanqamar@ukm.edu.my \\ 2 The School of Electrical, Computer and Telecommunications Engineering, Faculty of Engineering and \\ Information Sciences, University of Wollongong, Wollongong, NSW 2522, Australia; \\ maraj.siddiqui@gmail.com \\ 3 Department of Electrical Engineering, Faculty of Engineering, University of Malaya, \\ Kuala Lumpur 50603, Malaysia; drnourhindia@gmail.com \\ 4 Network and Communication Technology (NCT) Lab, Centre for Cyber Security, Fakulti Teknologi \& Sains \\ Maklumat (FTSM), Universiti Kebangsaan Malaysia (UKM), UKM, Bangi, Selangor 43600, Malaysia \\ 5 Department of Communications and Computer Engineering, School of Fundamental Science and \\ Engineering, Waseda University, Shinjuku-ku, Tokyo 169-0051, Japan \\ * Correspondence: rosilah@ukm.edu.my (R.H.); quang140788@gmail.com or \\ quang.nguyen@aoni.waseda.jp (Q.N.N.)
}

Received: 21 July 2020; Accepted: 27 August 2020; Published: 1 September 2020

\begin{abstract}
With an extensive growth in user demand for high throughput, large capacity, and low latency, the ongoing deployment of Fifth-Generation (5G) systems is continuously exposing the inherent limitations of the system, as compared with its original premises. Such limitations are encouraging researchers worldwide to focus on next-generation 6G wireless systems, which are expected to address the constraints. To meet the above demands, future radio network architecture should be effectively designed to utilize its maximum radio spectrum capacity. It must simultaneously utilize various new techniques and technologies, such as Carrier Aggregation (CA), Cognitive Radio (CR), and small cell-based Heterogeneous Networks (HetNet), high-spectrum access (mmWave), and Massive Multiple-Input-Multiple-Output (M-MIMO), to achieve the desired results. However, the concurrent operations of these techniques in current 5G cellular networks create several spectrum management issues; thus, a comprehensive overview of these emerging technologies is presented in detail in this study. Then, the problems involved in the concurrent operations of various technologies for the spectrum management of the current $5 \mathrm{G}$ network are highlighted. The study aims to provide a detailed review of cooperative communication among all the techniques and potential problems associated with the spectrum management that has been addressed with the possible solutions proposed by the latest researches. Future research challenges are also discussed to highlight the necessary steps that can help achieve the desired objectives for designing 6G wireless networks.
\end{abstract}

Keywords: 6G; spectrum management; 5G; Carrier Aggregation (CA); Cognitive Radio (CR); small cell; high-spectrum access; mmWave; M-MIMO

\section{Introduction}

Given the exponential increase in high-definition multimedia applications, the simultaneous communication among various connected devices with new features, and the massive user demand 
for data, the mobile data traffic must be boosted by $1000 \times$ [1]. Records show that the amount of data managed by wireless systems has increased from under 3 exabytes in 2010 to over 190 exabytes in 2020; therefore, if a data request is carried with the same speed, the demand for data is expected to grow by more than 500 exabytes by 2025 and beyond [2]. This expected leap of high mobile data demand and other machine-type communication services makes it necessary to ponder on the requirements for future 6G networks [3]. Spectral efficiency, energy efficiency, high bandwidth, and low power consumption are regarded as a critical challenge and should be considered before designing $6 \mathrm{G}$ networks $[4,5]$. To substantiate future data necessities and support a diverse set of devices, New Radio (NR) 6G networks are predicted to meet these demands with competently managed spectrum resources [6]. According to researchers, NR is a combination of various radio access technologies that help supply expected data with low latency, high-spectrum efficiency, and low power consumption [7]. It is broadly classified as low-power small cells utilizing the millimeter-wave (mmWave) spectrum, considering effective use of an unlicensed spectrum of Wi-Fi in a $5 \mathrm{GHz}$ band and the implementation of Massive Multiple-Input-Multiple-Output (M-MIMO) technology instead of the conventional $2 \times 2$ MIMO system [8]. The utilization of high-spectrum access, i.e., mmWave frequency band [9], Cognitive Radio (CR) [10], M-MIMO [11], Cooperative Networks (CNs) using Relay Nodes (RNs) [12], Coordinated Multipoint Operation (CoMP) [13], Wireless Sensor Networks (WSN) [14], Mobile Ad Hoc Networks (MANETs) [15,16], Device-to-Device (D2D) communication [17], Internet of Things (IoT) [18,19], Ethernet Passive Optical Networks (EPON) [20], Heterogeneous Networks (HetNet) [21], and cellular cloud computing, including big data [22], are some of the current approaches that can be modified to deliver the $6 \mathrm{G}$ requisites. Moreover, the use of various power optimizations [23,24], handover processes [25], interference cancellation [26], data security management [27], routing protocols [28], and scheduling algorithms [29] with optimal enhancement can also deliver ultimate results. New approaches, such as satellite communication at the mmWave spectrum [30], Artificial Intelligence (AI)-based micro Base Stations (BSs) [31], machine learning-based communication [32,33], blockchain [34], and human-centric communication [35], are some promising ideas for designing $6 \mathrm{G}$ networks.

Furthermore, in 6G radio access technologies, Spectrum Sharing (SS) and Radio Resource Management (RRM) are a critical part of the design of a future network [36]. Looking after and using the spectrum resources wisely are important when moving toward a new frequency spectrum, specifically in the mmWave frequency band [37]. The demand for a new spectrum has increased tremendously as the number of users and diverse electronic communication devices expands exponentially [38]. On this basis, the available spectrum has minimal resources and cannot deliver the $1000 \times$ expansion in users and devices with high data requirements [39]. Additionally, the technologies and techniques that followed Long-Term Evolution (LTE), LTE-Advanced (LTE-A), and its predecessors cannot provide prosperous results for future wireless communication [40]. Therefore, new spectrum resources and advanced technologies must be determined to address the upcoming high data requirement for low latency and extend the services to another decade and even more [41]. Nevertheless, the simultaneous operation of new technologies in a cellular network structure results in many management issues [42]. Standardization organizations, research institutions, and governments of various countries focus on 5G spectrum strategies and their effective usage [43]. The International Telecommunication Union (ITU), European Telecommunications Standards Institute (ETSI), and Federal Communications Commission (FCC) are the respective standardization organizations in the telecommunications industry that focus on designing new mobile communication technologies [44,45].

Future cellular communication networks are considered ultra-dense; thus, a robust and frugal network must be designed to accommodate numerous users with fairness in high throughput and perform spectrum management systematically [46,47]. To enhance the spectral efficiency of cellular networks, an ultra-dense small cell design can help achieve the objectives of future 6G cellular networks [48]. Concurrent operations of macro-cells and low-power small cells, such as picocells, femtocells, and RNs with wired and wireless backhaul links, are known as HetNet [49]. Adding the 
structure of many small cells conveys two positive outcomes: (1) it reduces the load on a BS where numerous users compete to access the resources, and (2) it helps use the frequency spectrum efficiently [47]. Thus, this method substantially improves the throughput for each user and provides fairness among the users. However, ultra-dense small cell systems face some serious challenges, such as interference, which is a major issue in HetNet deployment [50]. In addition, supporting mobility in small cells leads to the increasing cost of installation, maintenance, and backhaul structure [51].

While researching on the MIMO technology for 6G goals, M-MIMO undoubtedly supports power utilization and spectrum management efficiencies [52,53]. Conventional MIMO is equipped with two to four antennas, whereas M-MIMO can use tens and hundreds of antennas for the simultaneous transmission and reception of multiple signals over the same channel [54]. This method greatly boosts the network capacity and accommodates the maximum number of users and devices on the same frequency band, thereby reducing the usage of spectra. To maximize M-MIMO properties effectively, a technique called beamforming can be used to deliver the desired results $[55,56]$. The use of CR, which plays a vital role in spectrum management, is another novel idea. CR is an intelligent wireless network technology that can automatically detect available channels in a cellular spectrum. It can be implemented with the M-MIMO system to enable communication and execute simultaneously, besides improvised cellular operational performance [57]. M-MIMO is efficiently handy for networks to which many users connect (i.e., IoT) [58,59].

Another feature of current $5 \mathrm{G}$ communication is access to the mmWave spectrum [60]. However, previously, it was considered unsuitable for cellular communication because of its propagation characteristics, inability to travel over long distances due to its short wavelength, and penetration losses due to objects and large structures and adverse atmospheric conditions [61]. However, the densification of small cell networks and the parallel operation of innovative methods make the use of the mmWave frequency band possible [62]. Even though most of the spectrum is unused in this region, the Third-Generation Partnership Project (3GPP) already mentioned in its release 15 and 16 that it is not harmful to utilize for wireless communication [63,64]. The 3GPP defines an NR 5G spectrum with two different sets of frequency bands. The first is frequency range $1(<6 \mathrm{GHz})$, where the frequency using this region for $5 \mathrm{G}$ is approximately $3.5 \mathrm{GHz}$, and the maximum channel bandwidth available is $100 \mathrm{MHz}$ [65]. As stated by the FCC, most of the spectrum used in this range is for $4 \mathrm{G}$ and its progenitor technologies [66]. By contrast, frequency range 2 ( $>24 \mathrm{GHz}$, i.e., mmWave frequency band) is where the maximum channel bandwidth is defined to be as low as $50 \mathrm{MHz}$ to a maximum of $400 \mathrm{MHz}$ [67].

The goal of 6G is to meet the needs of the information society ten years later (2030 ); thus, the $6 \mathrm{G}$ vision must address the needs that $5 \mathrm{G}$ cannot meet and the need for further up-gradation [68]. 6G must be developed in response to the increasingly distributed Radio Access Network (RAN) and the desire to maximize the Terahertz (THz) spectrum for increasing capacity and reducing latency [69]. The 6G wireless system must have the following key factors: enhanced Mobile Broadband (eMBB), Ultra-Reliable Low Latency Communications (URLLC), massive Machine-Type Communication (mMTC), AI-integrated communication, tactile internet, low backhaul, and access network congestion and enhanced data security [70-73]. In summary, the future 6G is a set of technologies that can deliver the optimum results in terms of throughput, network capacity, spectral efficiency, energy efficiency, lower power consumption, and latency, ensuring fairness among all the users, especially the cell-edge users [74].

\section{Contribution}

The future 6G network is expected to deliver high data rates to each user to run high-definition applications, which are facing various challenges with the current $5 \mathrm{G}$ network. Typically, the $6 \mathrm{G}$ network supports a diverse range of applications and services, including enhanced indoor coverage, large capacity for outdoor public spaces, improved spectral efficiency, and low power consumption [75]. To support essential user applications and increase the efficiency of communications among interconnected devices with low latency and high throughput, primary technologies are expected to 
achieve the goals of $6 \mathrm{G}[76,77]$. This study aims to describe the techniques involved in current $5 \mathrm{G}$ network design and their issues, in accordance with spectrum management for designing future 6G networks. The five major topics covered in this study are Carrier Aggregation (CA), CR, small cell, high-spectrum access, and M-MIMO (Figure 1). The main concept of each of the involved approaches and their potential results in current $5 \mathrm{G}$ is also presented. Furthermore, research issues are discussed in this study.

Carrier Aggregation: The current 5G network is compatible with its predecessor's technologies, including Carrier Aggregation (CA). CA was first introduced in 4G LTE, and it is now implemented in the current 5G system. The core objective of CA is to utilize the spectrum resources of a cellular network effectively.

Cognitive Radio: Another promising technology for the current 5G system is CR. It is an adaptive and advanced radio network technique that can automatically discover available channels in a wireless cellular spectrum.

Small Cell: To support numerous users of up to almost 100 times more than that of the previous network, small cells with Full-Duplex (FD) communication are introduced to resolve the spectrum issues.

High-spectrum Access: Accessing high-spectrum assets is inevitable due to the scarcity of available spectrum resources. A new high-spectrum space, i.e., mmWave frequency bands, ranges from $24 \mathrm{GHz}$ to $300 \mathrm{GHz}$.

M-MIMO: It allows the simultaneous transmission and reception of more than one signal over the same channel. Standard MIMO comprises two to four antennas, whereas the M-MIMO network contains several antennas for transmitting and receiving data. No preset figure is required, but in M-MIMO, we can implement $10 \mathrm{~s}$ and even $100 \mathrm{~s}$ of antennas for transmitting and receiving data over a common channel.

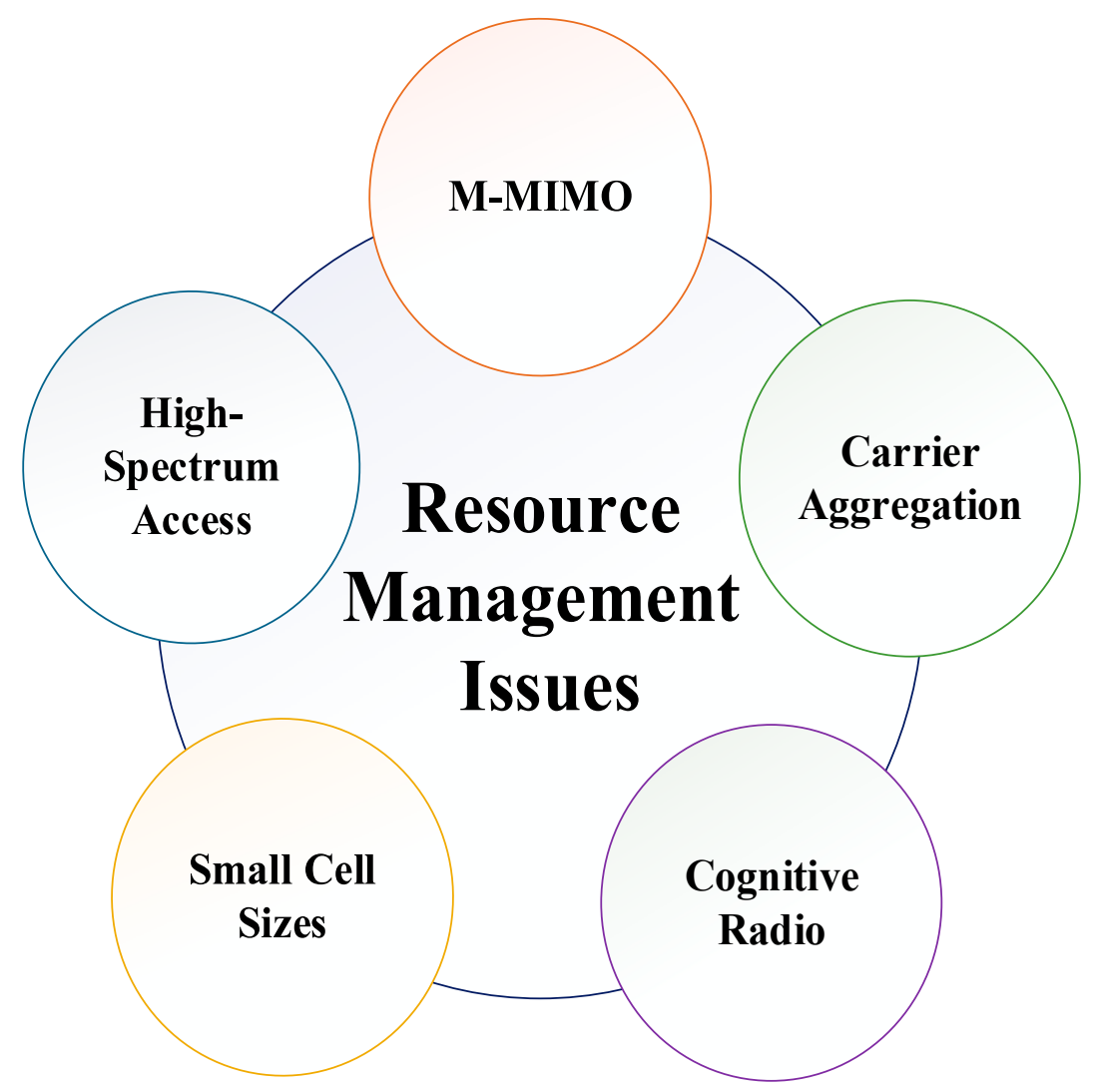

Figure 1. Spectrum management issues. 


\section{Spectrum Management Issues}

This section addresses the overview, challenges arises, and recent studies available in the literature related to spectrum management for the designing of the future wireless network.

\subsection{A. Carrier Aggregation}

One of the ways to achieve the extensive bandwidth required for the next-generation 6G network is through the CA technique [78]. For the current 5G network, CA or channel bonding (between the licensed and unlicensed carriers) is considered an efficient technique, although it can be used further by effectively handling the frequency resources for designing 6G networks [79]. CA can be implemented in three different methods, which can be identified based on the patterns in which the Component Carriers (CCs) are arranged (Figure 2) [80]. These methods include (a) intra-band contiguous in which a wide contiguous bandwidth of more than $20 \mathrm{MHz}$ is utilized, as in LTE-A [81,82]. Because of the frequency allocation strategies as it is today, this may be a less likely scenario but can function in some situations, as a $3.5 \mathrm{GHz}$ frequency band allocates in broadband [83]. The next method is (b) intraband noncontiguous in which the CCs work in the same spectrum as that of contiguous; this method can be used and aggregated for data transmission while adjacent resources are unavailable [84]. The last method is (c) interband noncontiguous in which communications are performed by simultaneously using two or more different operating frequency spectra, such as $800 \mathrm{MHz}$ and $2 \mathrm{GHz}$ bands [85]. In this manner, various wireless transmission attributes of varying frequency channels can be used to improve the robustness of mobility [86]. In the context of the physical layer, contiguous CA can be easily implemented without much modification to the LTE-A physical layer design [87]. To attain contingency in CA and support previous generation compatibility, i.e., LTE-A UE unit, a single Fast Fourier transform (FFT) module and a single Radio Frequency (RF) unit can be utilized [88]. In most cases, for both non-contiguous CA bands, multiple FFT and RF chains are mandatory. From the perspective of management and resource allocation, contiguous CA is also applicable [89]. Different CCs usually experience various Doppler shifts and path loss propagation characteristics that greatly affect network performance [90]. Several studies have been performed in CA, which helps maximize the use of the spectrum. Some of the recent studies that focus on four important areas, i.e., resource sharing, energy efficiency, capacity improvement, and transmission performance, are discussed below.

(a) Intra-band
contiguous
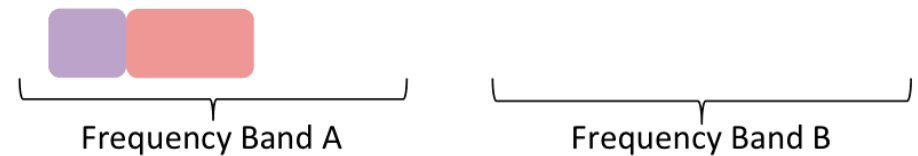

(b) Intra-band non-contiguous
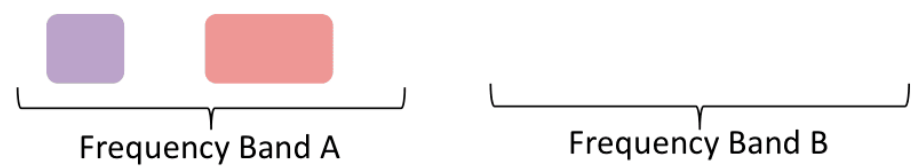

(c) Inter-band non-contiguous
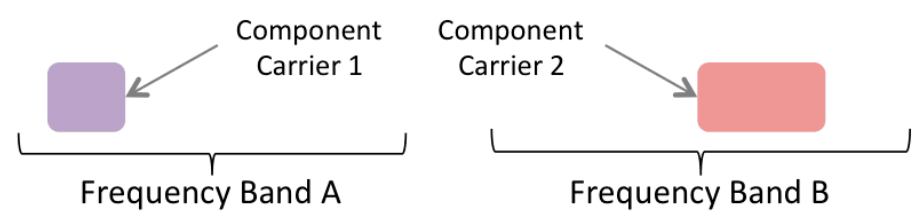

Figure 2. Carrier Aggregation types.

\subsubsection{Resource Sharing}

The authors in [91] have discussed the RRM shortcomings of the currently utilized CA technique. The issues persist with the CC selection and Resource Block (RB) allocation of selected CCs, as mentioned in 4G standards. Nevertheless, a method is developed on the basis of the head of line delay and delay 
threshold, which enhances the overall data rate and Quality of Service (QoS) of the user, with low computational complexity. However, no significant outcome is observed in user fairness. In [92], researchers suggest fewer studies that have been undertaken on the findings of several performance parameters on the packet scheduling algorithm in the CC system. Therefore, a newer and orderly scheduling algorithm of packets is considered for multiple CC systems on fair criteria equivalence for downlink propagation. The technique supports real and non-real-time traffic with good energy efficiency and better utilization of spectrum resources. However, the performance results of the designed algorithm based on overall system throughput, fairness, and mean delay largely improve in comparison with those algorithms of independent CC without aggregated. The resource allocation and joint optimization of CC selection are observed in the current 5G CA system in the study [93], and the researchers have delivered a greedy-based algorithm method to resolve the issue. Therefore, the proposed technique helps improve performance by comparing existing schemes and computational complexity at an acceptable level. In another study [94], authors have worked on an enhanced method of CC selection algorithm to overcome the issues of the existing CC selection scheme. An innovative channel quality and traffic load algorithm approach are used in each CC. The simulation output shows that downlink performance is vastly improved as a newly designed CC selection approach provides high throughput and good QoS to all user equipment. However, the method still suffers from power equality when the number of users in a cell is high.

\subsubsection{Energy Efficiency}

The authors in [95] have highly focused on the energy efficiency of a system alongside capacity and coverage fairness for users. This study has analyzed the outage capacity of a system and proposed a relaying scheme on energy-efficient methods to maximize the capacity, coverage, and fairness of CA-based networks. This relaying method also enhances low-frequency CCs for greater capacity fairness among all users in a cell. Conversely, an advanced and efficient algorithm is still in demand for user mobility. Another energy-efficient multi-stream Carrier Aggregation for HetNet is proposed in [96]. It utilizes a Bisection Method for Energy Minimization (BIMEM) algorithm to minimize energy consumption and capacity maximization by analyzing the problem as multi-objective optimization. The results have proved that the trade-off curve between energy minimization and capacity maximization delivers a large amount of energy savings by reducing the network capacity.

\subsubsection{Capacity Improvement}

The authors in [97] have focused on the issue of network capacity maximization in the CA. The approach is based on the joint cell association and user scheduling; in this approach, the user can connect BSs by using multiple carrier bands. This technique helps solve convex optimization issues, but it suffers from high computational complexity when the number of users in the cell is high. Another study on increasing radio resource efficiency has focused on adaptive CA with differentiated cloud services [98]. It proposes a cross-layer scheduling approach based on three mechanisms: (1) Markov Decision Process-Based Cost Reward Packet Selection (MDP-PS), (2) Adaptive Packet Scheduling (APS), and (3) Adaptive Component Carrier Scheduling (ACCS). The simulation results have proved that the suggested method delivers improved results for capacity, network reward, and packet failure rate; however, authors have suggested that an analytical method for C-RAN (Cloud/Centralized Radio Access Network) and energy-efficient CR techniques are needed for future cellular networks.

\subsubsection{Transmission Performance}

Another study [99] has proposed a novel design of the receiver for CA LTE-A and NR for the current 5G network. It has implemented the cascade-shutoff low-noise transconductance amplifier method. Consequently, the proposed generic receiver structure supports inter-band and intra-band CA with various CA scenarios, and the single-gm receiver design provides good linearity, especially for out-of-band blockers; however, it is limited to Single-Input-Multiple-Output scenarios. The authors 
in [100] have proposed a latency-efficient Code-Division Multiplexing (CDM) CA approach, which is based on the least-squares approximation. This approach helps mitigate the Peak-To-Average Power Ratio (PAPR) for the scenario of 5G NR Mobile Fronthaul (MFH). The results show that the approach can reduce the number of iteration and latency with efficient transmission performance.

Below is Table 1, which summarizes the techniques, advantages, and limitations of the above-discussed studies.

Table 1. Summary of the related work for Carrier Aggregation (CA).

\begin{tabular}{|c|c|c|c|c|}
\hline Approach & Methodology/Technique & Advantages & Limitation/Future Work & References \\
\hline \multirow{4}{*}{ Resource sharing } & $\begin{array}{l}\text { Component Carrier }(\mathrm{CC}) \\
\text { selection based on the head of } \\
\text { the line delay and } \\
\text { threshold delay }\end{array}$ & $\begin{array}{l}\text { Increase network } \\
\text { throughput and reduce } \\
\text { computational } \\
\text { complexity }\end{array}$ & $\begin{array}{l}\text { No improvement in } \\
\text { fairness index }\end{array}$ & [91] \\
\hline & $\begin{array}{l}\text { Design an efficient packet } \\
\text { scheduling algorithm based } \\
\text { on proportional fairness to use } \\
\text { in multiple CC's systems }\end{array}$ & $\begin{array}{l}\text { Support both real and } \\
\text { non-real-time traffic }\end{array}$ & $\begin{array}{l}\text { Inefficient when packet } \\
\text { traffic is fluctuating }\end{array}$ & [92] \\
\hline & $\begin{array}{l}\text { Joint optimization technique } \\
\text { based on a greedy-based } \\
\text { algorithm for CC selection }\end{array}$ & $\begin{array}{l}\text { Computational } \\
\text { complexity } \\
\text { is decreased }\end{array}$ & $\begin{array}{l}\text { Low fairness index for } \\
\text { cell-edge users }\end{array}$ & [93] \\
\hline & $\begin{array}{l}\text { Traffic and channel-driven CC } \\
\text { selection by considering } \\
\text { channel quality and } \\
\text { traffic load }\end{array}$ & $\begin{array}{l}\text { Better performance as } \\
\text { compared to least-load } \\
\text { and max channel } \\
\text { quality indicator } \\
\text { (CQI) algorithm }\end{array}$ & $\begin{array}{l}\text { Low fairness index when } \\
\text { a high number of users } \\
\text { in a cell }\end{array}$ & [94] \\
\hline \multirow[b]{2}{*}{ Energy efficiency } & $\begin{array}{l}\text { Relaying scheme to improve } \\
\text { the coverage, fairness, and } \\
\text { capacity for CA-based system }\end{array}$ & $\begin{array}{l}\text { Work for both } \\
\text { intra-and } \\
\text { inter-band CA }\end{array}$ & $\begin{array}{l}\text { More advance algorithm } \\
\text { is needed for the } \\
\text { mobility of users }\end{array}$ & [95] \\
\hline & $\begin{array}{l}\text { The Bisection Method for } \\
\text { Energy Minimization } \\
\text { (BIMEM) algorithm is used to } \\
\text { minimize the energy } \\
\text { consumption and capacity } \\
\text { maximization }\end{array}$ & $\begin{array}{l}\text { Reducing network } \\
\text { capacity and improves } \\
\text { massive energy saving }\end{array}$ & $\begin{array}{l}\text { Interference effect due to } \\
\text { multiple BSs on the } \\
\text { same layer }\end{array}$ & [96] \\
\hline \multirow[b]{2}{*}{$\begin{array}{c}\text { Capacity } \\
\text { improvement }\end{array}$} & $\begin{array}{l}\text { User scheduling and } \\
\text { combined cell association, } \\
\text { where the user can connect } \\
\text { BSs by using multiple } \\
\text { carrier bands }\end{array}$ & $\begin{array}{l}\text { Convex optimization } \\
\text { solutions to enhance } \\
\text { the network capacity }\end{array}$ & $\begin{array}{l}\text { Computational } \\
\text { complexity increases for } \\
\text { high users }\end{array}$ & [97] \\
\hline & $\begin{array}{l}\text { Cross-layer scheduling } \\
\text { approach based on three } \\
\text { mechanisms: (1) Markov } \\
\text { Decision Process-Based Cost } \\
\text { Reward Packet Selection } \\
\text { (MDP-PS), (2) Adaptive Packet } \\
\text { Scheduling (APS), and (3) } \\
\text { Adaptive Component Carrier } \\
\text { Scheduling (ACC) }\end{array}$ & $\begin{array}{l}\text { Better results for } \\
\text { capacity, network } \\
\text { reward, and packet } \\
\text { failure rate }\end{array}$ & $\begin{array}{l}\text { An analytical method is } \\
\text { needed for centralized } \\
\text { radio access network } \\
\text { (C-RAN) and } \\
\text { energy-efficient } \\
\text { cognitive radio }(\mathrm{CR})\end{array}$ & [98] \\
\hline \multirow{2}{*}{$\begin{array}{l}\text { Transmission } \\
\text { performance }\end{array}$} & $\begin{array}{l}\text { Receiver design architecture } \\
\text { based on cascade-shutoff } \\
\text { Low-Noise Transconductance } \\
\text { Amplifier (LNTA) }\end{array}$ & $\begin{array}{l}\text { Support both } \\
\text { inter-band and } \\
\text { intra-band }\end{array}$ & $\begin{array}{l}\text { Limited to } \\
\text { Single-Input-Multiple-Output } \\
\text { (SIMO) scenario only }\end{array}$ & [99] \\
\hline & $\begin{array}{l}\text { A latency-efficient } \\
\text { Code-Division Multiplexing } \\
\text { (CDM) CA approach based on } \\
\text { least-squares approximation }\end{array}$ & $\begin{array}{l}\text { Reduce the number of } \\
\text { iteration and latency }\end{array}$ & $\begin{array}{l}\text { Limited transmission } \\
\text { distance of maximum } \\
10 \mathrm{~km}\end{array}$ & [100] \\
\hline
\end{tabular}

\subsection{Cognitive Radio}

One of the prominent strategies to attain a high level of spectrum resource optimization required for the current $5 \mathrm{G}$ is through a flexible sharing and allocation of available spectrum resources through flexible and opportunistic usage [101]. The existing spectrum regulatory policies do not encourage 
flexible frequency utilization and opportunistic spectrum access in the cellular systems. Recently, the FCC has committed to the implementation of the shared utilization of the $3550-3650 \mathrm{MHz}$ bands [102]. CR, based on a software-defined radio, offers the opportunity for flexible spectrum access in wireless systems [103]. It is also regarded as one of the key players of the current 5G cellular network. CR work is classified into three main sections, namely, spectrum management, intelligence management, and interference management [104]. Spectrum management determines and manages various spectrum issues for primary and secondary users [105-107]. Intelligence management is built on an efficient cognitive engine that uses a diverse range of synthetic intelligence methods (e.g., genetic algorithm and rule-based systems) and neural networks to manage the network resources [108,109]. Interference management focuses on the implementation aspect of the $C R$, which involves various characteristics of the radio channels (such as resource allocation for the users), in addition to link quality and channel awareness, which highly depend on the precise selection of transmission power [110].

Small cells have low transmission power; thus, the coverage areas under such small cells can apply CR for efficient resource optimization and high data rate services [111]. To utilize the CR paradigm in the most efficient way for higher throughput, spectrum sensing is a fundamental element in it. Moreover, its methodology is close to the spectrum opportunity definition [112]. Spectrum sensing can be presented in three different scenarios, namely, (a) local spectrum sensing by the small cell BS; (b) centralized cooperating spectrum sensing, where users are activated by the small cell BS, apply spectrum sensing, and deliver the outcomes to the small cell BS that serves, performs as a central unit; (c) distributed cooperating spectrum sensing, where users are activated by the small cell BS, apply spectrum sensing, and report the consequences to the closest neighbors, as shown in Figure 3. A considerable portion of radio spectrum resources is largely underutilized in most cases and has necessitated the adoption of CR to maximize resource usage [113]. In [114], the authors have suggested that the concept of spectrum allocation through SS is used mainly for optimal spectrum usage, especially for small cells. Given that spectrum allotment is under the governance and control of regional regulatory authorities and policies, the prospective newly licensed bands in each region probably lie in the range of 3-10 GHz, whereas the $95-150 \mathrm{GHz}$ bands can be obtained through the SS mechanism facilitated by opportunistic utilization [115]. Several types of research have been conducted on spectrum management issues related to spectrum sensing, throughput enhancement, spectrum allocation, channel estimation and optimization, and cluster formation. A few of the latest studies are discussed in further subsections.

\subsubsection{Spectrum Sensing}

Another spectrum sensing approach has been presented for real-time configuration [116]. The idea is to utilize the Filter Bank Multicarrier (FBMC) approach, which is based on the adjustment by using the non-linear fractional program and stationery Karush-Kuhn-Tucker (KKT) condition. It helps achieve the efficient utilization of network resources that can be used for IoT applications. The authors have suggested that in the future, various bio-inspired optimization techniques can be used for efficient $\mathrm{CR}$ integration. Another method to minimize interference and enhance sensing accuracy is discussed in [117]. It is a group-based multichannel synchronized spectrum sensing approach that is based on the Dynamic Multi-Channel Slot Allocation (DMCSA) algorithm. The idea is to introduce a special entity, i.e., a spectrum agent that is used to execute only spectrum sensing and report to the fusion center. The extracted results have proved that the proposed technique could deliver optimal performance in terms of throughput, detection probability, delay, and sensing overhead. 


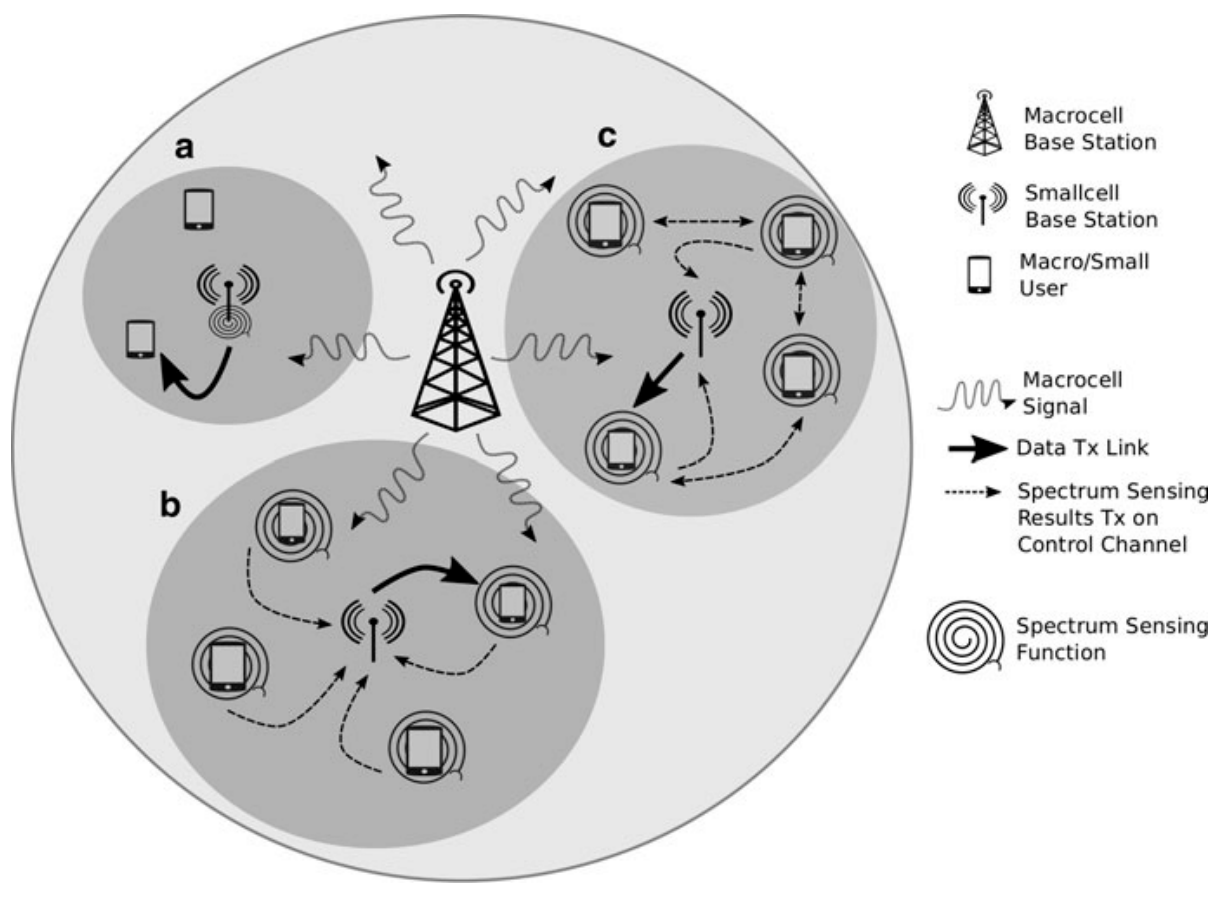

Figure 3. Cognitive Radio (CR)-based spectrum sensing.

\subsubsection{Throughput Enhancement}

In [118], the authors have investigated equilibrium strategic behavior for two classes of users, i.e., Primary User (PU) and Secondary User (SU) based on three information cases, namely, no queue length information, partial queue length information, and full queue length information for $C R$ systems. An efficient approach using theoretical and numerical analyses is derived to enhance PU and SU performance. The study has concluded that with minimum sojourn time, improved QoS and throughput can be achieved, but the increase in service rate does not necessarily improve the data rate of the CR network. Therefore, a more robust and precise algorithm is required. In the account of future work, the designed model can be further extended to trilateral work among the PU, SU, and manager of the CR system. A detailed study on the congested routes for PUs in the CR network is performed [119]. The undercover routing protocol technique is introduced with a joint venture of three-layer routings and beamforming methods. The proposed protocol is evaluated via NS2 simulations, and the results show that it enhances the goodput to up to $250 \%$ in comparison with other routing protocols with lower overhead. For future recommendations, a technique to improve group construction time remains a challenge.

\subsubsection{Spectrum Allocation}

In [120], the authors have worked on expanding the utilization of the available spectrum by dynamically assigning channels to SUs, and this problem is considered a spectrum allocation problem. A method called Chaotic Biogeography-Based Optimization (CBBO) evolutionary algorithm is derived. The results show that $\mathrm{CBBO}$ is a generally suitable optimizer for solving combinational optimization problems. Therefore, the technique enhances or at least maintains the performance of the other algorithms in the CR network. In the future, one can work on the same model that can use QoS parameters for nonlinear migration models and on the application of BBO in next-generation technologies. A study [121] has suggested to resolving the issue of spectrum management requirements and heterogeneity for the CR users. The study has provided an innovative Channel Management Framework (CMF) for CR sensor networks. The framework is strongly constructed on Opportunity Scheduler (OSR), Opportunity Detector (ODR), and Opportunity Ranker (ORR) to tackle the shortcomings of $\mathrm{CR}$ sensor network-aided IoT. Consequently, the proposed CMF scheme surpasses all 
current methods with respect to blocking and detection probability, collision probability, and idle time probability, and throughput. In the future, a system that uses a single optimization problem to execute ORR and ODR can be designed.

\subsubsection{Channel Estimation and Optimization}

The limiting factor that has been left as a challenge is designed as a multilayer complex algorithm for the more agile cluster. In [122], a channel status evaluation parameter, i.e., Signal-to-Noise Ratio (SNR), is observed. The research is conducted by implementing the Second- and Fourth-Order Moment technique based on Kalman filter theory. The simulation proves that in the range of SNR (0-15 dB), the estimation and prediction methods exhibit low error rates with a high prediction error of up to $0.14 \mathrm{~dB}$. Therefore, this method is viable and can be utilized to estimate the channel quality of the CR system. The authors in [123] have presented an energy-efficient resource allocation for the CR-enabled 5G network and proposed an alternative optimization framework to optimize the variables of subcarrier assignment and power allocation. It has adopted a heuristic subcarrier assignment and a convex approximation technique. The results are estimated to achieve efficient energy efficiency in comparison with the conventional resource allocation scheme. However, the proposed approach is based on some impractical assumptions, such as a single user in one cell, a single antenna for transmitter and receiver, and well-synchronized PUs and SUs.

\subsubsection{Cluster Formation}

The authors in [124] have proposed a weight-based cluster formation scheme to overcome the clustering issues caused by node mobility and dynamic channel availability in the CR network. Furthermore, they have compared their designed protocol with competing protocols in the CR network. Subsequently, the developed algorithm produces better results than conventional protocols, especially in adverse conditions. Another cluster-based scheduling approach is proposed in [125]. The authors have proposed two scheduling approaches, i.e., Frame Intra Cluster Multichannel Scheduling algorithm denoted Frame-ICMS and the Slot Intra Cluster Multichannel Scheduling algorithm denoted Slot-ICMS. The performance is evaluated in terms of accurate and bad PU activity. It enables spatial reuse with noninterfering users, reduces delays, and saves energy.

The above-discussed researches have been summarized in Table 2.

Table 2. Summary of the related work for CR.

\begin{tabular}{|c|c|c|c|c|}
\hline Approach & Methodology/Technique & Advantages & Limitation/Future Work & References \\
\hline \multirow[b]{2}{*}{ Spectrum sensing } & $\begin{array}{l}\text { A new Filter Bank Multicarrier } \\
\text { (FBMC) approach based on } \\
\text { the adjustment by using the } \\
\text { non-linear fractional program } \\
\text { and stationery KKT condition }\end{array}$ & $\begin{array}{l}\text { Efficient utilization of } \\
\text { network resources for } \\
\text { real-time Internet of } \\
\text { Things (IoT) } \\
\text { applications }\end{array}$ & $\begin{array}{l}\text { Bio-inspired techniques } \\
\text { for more efficient } \\
\text { optimization approach }\end{array}$ & [116] \\
\hline & $\begin{array}{l}\text { A group-based multi-channel } \\
\text { synchronized spectrum } \\
\text { sensing approach based on } \\
\text { Dynamic Multi-Channel Slot } \\
\text { Allocation (DMCSA) } \\
\text { algorithm }\end{array}$ & $\begin{array}{l}\text { Optimal performance } \\
\text { in terms of throughput, } \\
\text { detection probability, } \\
\text { delay, and sensing } \\
\text { overhead }\end{array}$ & $\begin{array}{l}\text { Limited to a smaller } \\
\text { number of users }\end{array}$ & [117] \\
\hline \multirow{2}{*}{$\begin{array}{l}\text { Throughput } \\
\text { enhancement }\end{array}$} & $\begin{array}{l}\text { It derives an optimal service } \\
\text { rate for increasing the } \\
\text { performance of primary and } \\
\text { secondary users }\end{array}$ & $\begin{array}{l}\text { Better Quality of } \\
\text { Service (QoS) and } \\
\text { throughput } \\
\text { performance with } \\
\text { minimum sojourn time }\end{array}$ & $\begin{array}{l}\text { Queue length factor is } \\
\text { not considered }\end{array}$ & [118] \\
\hline & $\begin{array}{l}\text { The undercover routing } \\
\text { protocol, which consists of } \\
\text { collaborative beamforming } \\
\text { technique based on layer } \\
\text { three routing }\end{array}$ & $\begin{array}{l}\text { Gain increased up to } \\
250 \% \text { as compared to } \\
\text { conventional protocols }\end{array}$ & $\begin{array}{l}\text { Group construction time } \\
\text { needs to be improved }\end{array}$ & [119] \\
\hline
\end{tabular}


Table 2. Cont.

\begin{tabular}{|c|c|c|c|c|}
\hline Approach & Methodology/Technique & Advantages & Limitation/Future Work & References \\
\hline \multirow{2}{*}{$\begin{array}{l}\text { Spectrum } \\
\text { allocation }\end{array}$} & $\begin{array}{l}\text { The Chaotic } \\
\text { Biogeography-Based } \\
\text { Optimization (CBBO) } \\
\text { algorithm to solve } \\
\text { combinational } \\
\text { optimization problems }\end{array}$ & $\begin{array}{l}\text { CBBO performance is } \\
\text { higher as compared to } \\
\text { other traditional } \\
\text { algorithms }\end{array}$ & $\begin{array}{l}\text { Non-linear migration } \\
\text { model can be used } \\
\text { in future }\end{array}$ & [120] \\
\hline & $\begin{array}{l}\text { Channel Management } \\
\text { Framework (CMF) is } \\
\text { introduced which is based on } \\
\text { opportunity detector, } \\
\text { scheduler, and ranker }\end{array}$ & $\begin{array}{l}\text { Improvement in a } \\
\text { collision, blocking, } \\
\text { detection, and } \\
\text { idle-time probability }\end{array}$ & $\begin{array}{l}\text { Mobility factor is not } \\
\text { considered in } \\
\text { this scenario }\end{array}$ & [121] \\
\hline \multirow{2}{*}{$\begin{array}{l}\text { Channel estimation } \\
\text { and optimization }\end{array}$} & $\begin{array}{l}\text { The Second- And } \\
\text { Fourth-Order Moments } \\
\text { (M2M4) method is introduced } \\
\text { to calculate real-time Signal to } \\
\text { Noise Ratio (SNR) value }\end{array}$ & $\begin{array}{l}\text { Gives accurate and } \\
\text { reliable channel state } \\
\text { information }\end{array}$ & $\begin{array}{l}\text { The prediction error is } \\
\text { high as } 0.14 \mathrm{~dB}\end{array}$ & [122] \\
\hline & $\begin{array}{l}\text { An alternative optimization } \\
\text { framework to enhance the } \\
\text { variables of subcarrier } \\
\text { assignment and } \\
\text { power allocation }\end{array}$ & $\begin{array}{l}\text { Better energy efficiency } \\
\text { as compared to the } \\
\text { conventional resource } \\
\text { allocation scheme }\end{array}$ & $\begin{array}{l}\text { Limited to one user per } \\
\text { cell only }\end{array}$ & [123] \\
\hline \multirow[b]{2}{*}{ Cluster formation } & $\begin{array}{l}\text { Localized clustering technique, } \\
\text { which shares weight to } \\
\text { neighboring nodes to solve the } \\
\text { mobility issue }\end{array}$ & $\begin{array}{l}\text { Improves stability, } \\
\text { scalability, and efficient } \\
\text { spectrum management } \\
\text { with low } \\
\text { overhead delay }\end{array}$ & $\begin{array}{l}\text { Multi-layer complex } \\
\text { algorithm }\end{array}$ & [124] \\
\hline & $\begin{array}{l}\text { The cluster-based scheduling } \\
\text { approach is proposed, namely, } \\
\text { Frame- Intra Cluster } \\
\text { Multichannel Scheduling } \\
\text { algorithm (ICMS) and } \\
\text { Slot-ICMS. }\end{array}$ & $\begin{array}{l}\text { Enable spatial reuse } \\
\text { along with } \\
\text { non-interfering users }\end{array}$ & $\begin{array}{l}\text { The overhead } \\
\text { delay increases }\end{array}$ & [125] \\
\hline
\end{tabular}

\subsection{Small Cell}

The current 5G networks have been characterized by a combination of small cell networks, also known as HetNet, due to mmWave integration (Figure 4) [126,127]. A straightforward but exceedingly realistic way to maximize the network capacity is by reducing the cell sizes using the concept of network densification [128]. For instance, during the $1 \mathrm{G}$ era of cellular systems in the early 80s, the cell sizes used were basically in the order of hundreds of square km [129]. From $1 \mathrm{G}$ up to the present time, the cell sizes have been progressively decreasing and have recently been reduced to approximately $1 \mathrm{~km}$ for the outdoor and $100 \mathrm{~m}$ for the indoor scenario [130]. Nevertheless, cell reduction has several benefits, including high chances of frequency reuse across a given geographic area, resulting in a significant decrease in resource contention among users at each BS [131].

Several new techniques, including the utilization of RN, D2D, and IoT, also come to in design due to the small cell deployment network [126]. However, the small cells based on HetNet also suffer from several challenges due to the necessity of deploying additional BSs in a small geographical area. Consequently, it suffers from the limitation of energy-efficient power sources. In this regard, many BSs are operated entirely on various renewable energy sources, such as solar energy [132]. For example, the main issue that has caused a drawback to the use of small cells in HetNet is the interferences among the pico, macro, micro, and femtocells [133]. Given that the users are in the coverage of more than one cell, the interference causes many severe issues to achieve optimum results [134]. The interference can be of any type, such as intercell, intracell, BS to RN, and D2D interference. Many researchers are recently focusing on new approaches to mitigate this issue [135]. 


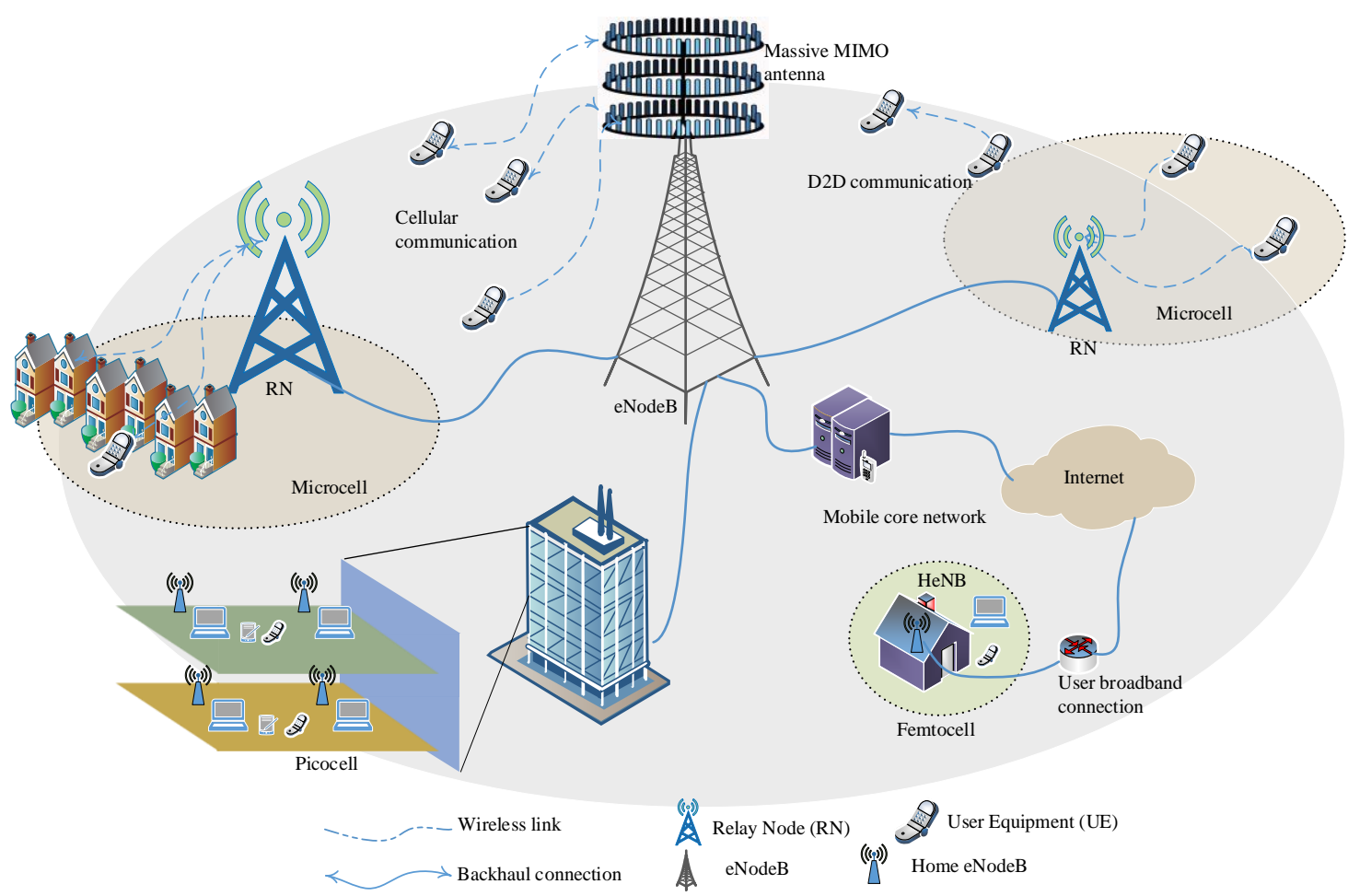

Figure 4. Small cell-based Heterogeneous Networks (HetNet).

Small cell networks face several other challenges, such as requiring additional frequency bands to facilitate each cell user [136]. The capacity of the cell depends on the number of active users and requires high bandwidths to achieve high throughput [137]. Moreover, fairness among cell-edge and cell-center users is also a big challenge [138]. The use of 5G small cells is based on the mmWave frequency band; these high-frequency signals are keen to degrade for several reasons, such as reflection, refraction, and diffraction. These factors are due to trees, buildings, or even the moving people in the coverage area, especially in urban environments [126]. The cost of the small cell network is also a big challenge that requires considerable attention; thus, the end-user should not be affected by this issue [139]. The backhaul connectivity of the small cell-based HetNet is essential in reducing the delay in transmission and in preventing the signal loss during the handover process performed by a user when it moves from one small cell to another [140]. Various major areas require considerable attention, such as interference avoidance, throughput improvement, coverage planning, and capacity enhancement. Several studies have been conducted to address these issues; some of the approaches are discussed in the succeeding subsections.

\subsubsection{Interference Avoidance}

The authors in [141] have presented a massive SS approach for in-building small cells. They have proposed a nonorthogonal interference-free SS approach to form 3D clusters and less distance among co-channel small cells. The results have demonstrated that the average spectral efficiency is substantially improved with the increase in the number of buildings, whereas energy efficiency is decreased with the increase in the number of buildings. Overall, the results have proved that the suggested nonorthogonal scheme is much better than the orthogonal spectrum for the Licensed Shared Access (LSA) and Licensed Assisted Access (LAA) methods in terms of sharing the $60 \mathrm{GHz}$ unlicensed spectrum. Another work in [142] focuses on designing small cell size networks that broadly check the issues of spectrum management. In particular, the researchers have focused on Wi-Fi and $4 \mathrm{G}$ wireless communication systems that share the unlicensed spectrum. They have introduced a novel network structure for both to utilize the unlicensed spectrum in the same proximity. They have also presented an Almost 
Blank Subframe (ABS) scheme to minimize interferences and proposed an interference avoidance scheme to cancel out the effect of types of interferences encountered by both technologies in a network. Consequently, the suggested architecture effectively contributes to cost reduction and interference avoidance; however, the transmission range is limited.

\subsubsection{Throughput Improvement}

The researchers in [143] have accomplished the task of delivering high QoS to each user by presenting a cache-enabled small cell network. In this scenario, optimal memory size is obtained in closed form for a provided density of a small BS. Hence, the outcomes indicate that equipping the optimal size of memory can minimize the capacity of backhaul and increases the throughput efficiency. Another RRM scheme is discussed in [144] for enhancing the performance of a small cell network. The idea is to propose a cooperative game radio resource-sharing scheme to improve the results for user throughput; moreover, spectral efficiency is better than that in the no-game scenario. The author has suggested that scaling up the environment for larger small cell networks requires additional distributed learning approaches that can be applied for efficient coalition formation.

\subsubsection{Coverage Planning}

The authors in [145] have discussed two critical tasks of mmWave small cell network, i.e., coverage and spectral efficiency. To evaluate the performance of spectrum resources, two techniques pursued are frequency reuse- 1 and frequency reuse- 3 . Similarly, an interference mitigation scheme is introduced to validate the performance of both scenarios. The researchers have also added points on how small cell radius inserts affect Multiuser MIMO (MU-MIMO) mode performance. Therefore, maximum throughput achieves almost $2.5 \times$ when three additional channels operate within a small radius of up to $50 \mathrm{~m}$. However, ultra-dense small cells are profoundly interfered with by intercell interferences; thus, an additional investigation is required on small cells. The author in [146] has focused on the issue of coverage holes (i.e., a location where a user does not receive an optimal signal level) in a macro to small cell two-layer network. To validate this shortage, an energy-efficient coverage approach is designed for implementation in a respective network. In conclusion, quality coverage, power usage, and average transmission rate are observed by utilizing the proposed algorithm for comparison with conventional methods. Regardless, a concrete algorithm that can extend to more than two-layer networks is required. A density-aware, energy-efficient, and spectrum-efficient sleep scheduling technique is presented in [147]. The solution is based on BS density adaptation and cell-zooming algorithms. The idea is to prevent a coverage hole and increase network throughput along with reducing Signal-to-Interference-plus-Noise Ratio (SINR) for cell-edge users. The results help improve throughput, energy, and spectral efficiency.

\subsubsection{Capacity Enhancement}

In [148], the authors focus on budgeted cell planning issues in the small cell network. Their results show high-spectral efficiency and capacity improvement for isolated mmWave MU-MIMO small cell users. Besides, a relay node can be introduced to enhance the coverage area in a small cell network. In [149], the authors have provided information for small cell networks, which focus on data offloading among users. They have furnished an innovative file cloud service mechanism to offload mobile user data when the demand for overall users increases. It can help share any kind of files and information from the users associated with the nearby small cell. To this end, mobile users conserve network capacity for high mobile data traffic. However, a delay is inevitable if the file size is extensive. Another research [150] has highlighted the issue of self-organizing small cell-based HetNet because its deployment suffers from challenges, such as backhauling, capacity provision, and dynamics in spatiotemporally fluctuating traffic load. To solve this issue, they set a mathematical model of an Artificial Immune System (AIS) that has the power to activate and deactivate the small cells as per the demand of traffic. Consequently, the recommended scheme helps deliver high throughput for 
cell-edge users and enhances BS activation speed. By contrast, if intercell interference is high, the cell activation and deactivation speed are also high.

Table 3 summarizes the above-discussed works for increasing the performance of small size cells.

Table 3. Summary of the related work for the small cell-based network.

\begin{tabular}{|c|c|c|c|c|}
\hline Approach & Methodology/Technique & Advantages & Limitation/Future Work & References \\
\hline \multirow[t]{2}{*}{$\begin{array}{l}\text { Interference } \\
\text { avoidance }\end{array}$} & $\begin{array}{l}\text { A non-orthogonal } \\
\text { interference-free Spectrum } \\
\text { Sharing (SS) approach to form } \\
\text { 3D clusters and less distance } \\
\text { among co-channel small cells }\end{array}$ & $\begin{array}{l}\text { Better results as } \\
\text { compared to the } \\
\text { orthogonal spectrum } \\
\text { for both Licensed } \\
\text { Shared Access (LSA) } \\
\text { and Licensed Assisted } \\
\text { Access (LAA) method }\end{array}$ & $\begin{array}{l}\text { The results for larger } \\
\text { small cell size need to be } \\
\text { investigated for the } \\
\text { validity of the } \\
\text { proposed approach }\end{array}$ & [141] \\
\hline & $\begin{array}{l}\text { It utilizes an Almost Blank } \\
\text { Subframe (ABS) scheme to } \\
\text { analyze the operation effect } \\
\text { between various small cells }\end{array}$ & $\begin{array}{l}\text { Proposed network } \\
\text { architecture delivers } \\
\text { cost-effective and } \\
\text { interference } \\
\text { avoidance results }\end{array}$ & $\begin{array}{l}\text { Limited transmission } \\
\text { range }\end{array}$ & [142] \\
\hline \multirow{2}{*}{$\begin{array}{l}\text { Throughput } \\
\text { improvement }\end{array}$} & $\begin{array}{l}\text { Optimal memory size is } \\
\text { calculated based on the user's } \\
\text { requesting probability }\end{array}$ & $\begin{array}{l}\text { The optimal size } \\
\text { memory delivers better } \\
\text { throughput } \\
\text { performance }\end{array}$ & $\begin{array}{l}\text { It reduces the } \\
\text { backhaul capacity }\end{array}$ & [143] \\
\hline & $\begin{array}{l}\text { A cooperative game } \\
\text { theory-based RRM scheme for } \\
\text { small cell network }\end{array}$ & $\begin{array}{l}\text { Results for user } \\
\text { throughput and } \\
\text { spectral efficiency are } \\
\text { better as compared to } \\
\text { no game scenario }\end{array}$ & $\begin{array}{l}\text { Distributed learning } \\
\text { approach can be applied } \\
\text { for more efficient } \\
\text { coalition formation }\end{array}$ & [144] \\
\hline \multirow{3}{*}{ Coverage planning } & $\begin{array}{l}\text { Spectral efficiency and } \\
\text { capacity improvement } \\
\text { technique for isolated } \\
\text { mmWave MU-MIMO small } \\
\text { cell users }\end{array}$ & $\begin{array}{l}\text { High throughput is } \\
\text { achieved when each } \\
\text { cell sector operates in } \\
\text { three channels }\end{array}$ & $\begin{array}{l}\text { Advanced interference } \\
\text { mitigation techniques } \\
\text { are required }\end{array}$ & [145] \\
\hline & $\begin{array}{l}\text { Mitigating the coverage hole } \\
\text { issue for a two-layer } \\
\text { small network }\end{array}$ & $\begin{array}{l}\text { Better coverage, power } \\
\text { usage, and } \\
\text { transmission rate }\end{array}$ & $\begin{array}{l}\text { A more efficient } \\
\text { algorithm is required to } \\
\text { support } \\
\text { higher-layer network }\end{array}$ & [146] \\
\hline & $\begin{array}{l}\text { Scheduling technique based } \\
\text { on BS density adaptation } \\
\text { algorithm and a } \\
\text { cell-zooming algorithm }\end{array}$ & $\begin{array}{l}\text { Better coverage, } \\
\text { throughput, and } \\
\text { spectral efficiency }\end{array}$ & $\begin{array}{l}\text { Can enhance work for } \\
\text { the mobility of BS }\end{array}$ & [147] \\
\hline \multirow{3}{*}{$\begin{array}{l}\text { Capacity } \\
\text { enhancement }\end{array}$} & $\begin{array}{l}\text { To enhance the number of } \\
\text { traffic demand nodes based on } \\
\text { power limited, bandwidth, } \\
\text { and traffic requirement }\end{array}$ & $\begin{array}{l}\text { Higher network } \\
\text { capacity with low } \\
\text { deployment cost }\end{array}$ & $\begin{array}{l}\text { Relay node can be added } \\
\text { to enhance the } \\
\text { coverage area }\end{array}$ & [148] \\
\hline & $\begin{array}{l}\text { The file cloud service is used } \\
\text { to offload the mobile user data } \\
\text { when the user's data } \\
\text { demand increases }\end{array}$ & $\begin{array}{l}\text { Higher accessibility } \\
\text { increases the } \\
\text { coverage area }\end{array}$ & $\begin{array}{l}\text { Delay increases with the } \\
\text { greater file size }\end{array}$ & [149] \\
\hline & $\begin{array}{l}\text { Design of a self-organizing } \\
\text { Artificial Immune System } \\
\text { (AIS) approach that activates } \\
\text { and deactivates small cells } \\
\text { concerning the traffic load }\end{array}$ & $\begin{array}{l}\text { Helps to increase the } \\
\text { coverage and cell-edge } \\
\text { user's throughput }\end{array}$ & $\begin{array}{l}\text { Activation and } \\
\text { deactivation process is } \\
\text { affected by interference }\end{array}$ & [150] \\
\hline
\end{tabular}

\subsection{High-Spectrum Access}

The channel characteristics of wireless communications mainly depend on several factors, namely, the radio spectrum used, the air-interface design type, and the network architecture [151]. Existing cellular networks, such as 4G, are operated in frequency bands under $6 \mathrm{GHz}$ because of the favorable channel propagation characteristics available in those frequency bands for cellular communications [152]. However, most of the frequency spectra below $3 \mathrm{GHz}$ are nearly used up, efforts to acquire new operating frequency bands for future terrestrial mobile communications have 
been intensified, and the primary focus has been shifted on the frequency spectrum in the mmWave bands [153]. One of the few potential solutions to address the envisaged issue of a capacity explosion in the next-generation radio network is by utilizing the massively untapped frequency resources. It can be divided into three different frequency ranges, i.e., (1) below $6 \mathrm{GHz}$ (sub-6 GHz), (2) NR mmWave (24-100 GHz), and (3) above $100 \mathrm{GHz}(100-300 \mathrm{GHz}$ ) (as shown in Figure 5) [154,155].

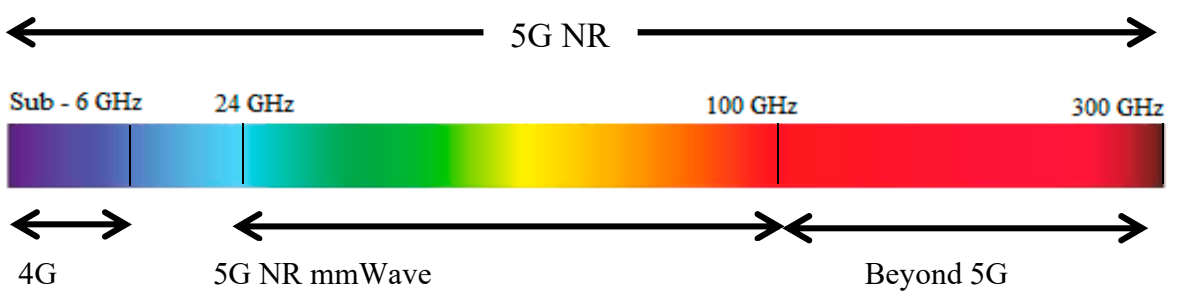

Figure 5. High-spectrum access (mmWave).

\subsubsection{Below $6 \mathrm{GHz}(\mathrm{Sub}-6 \mathrm{GHz})$}

The current $5 \mathrm{G}$ network is compatible with its predecessor's technologies, and the $4 \mathrm{G}$ spectrum sub- $6 \mathrm{GHz}$ can be easily applied for $5 \mathrm{G}$ communication [156]. The management and effective utilization of the current spectrum help avoid the unnecessary usage of mmWave frequency bands. For frequency bands under $6 \mathrm{GHz}$, the communication band between 3.5 and $4.2 \mathrm{GHz}$ is cleared for use with $5 \mathrm{G}$, and it can offer up to $300 \mathrm{MHz}$ of bandwidth [157]. This novel idea would have some of the following benefits: (1) The sub-6 GHz band can be used in the Line of Sight (LOS) and Non-Line of Sight (NLOS), (2) co-channel interferences between mmWave and small cells are negligible, and (3) the channel state information feedback rate for backhaul connection is smaller than that of $5 \mathrm{G}$ NR BS for user equipment fading links because of high mobility [158]. The transmission between macro BS and small cell BS would be a bottleneck due to high user capacity and interference-effect. Therefore, one of the prominent solutions to overcome the issue is to use sub-6 GHz for backhaul communication [159]. The sub- $6 \mathrm{GHz}$ band is also advisable to be used by users near macro BS for uplink and downlink transmission. Another author in [160] has focused on the effective implementation of the sub- $6 \mathrm{GHz}$ for 5G HetNet for wireless backhauling.

\subsubsection{NR mmWave (24-100 GHz)}

For high frequencies, such as $28 \mathrm{GHz}, 850 \mathrm{MHz}$ of bandwidth is available; for $39 \mathrm{GHz}$, two available bands offer 1.6 and $1.4 \mathrm{GHz}$ bandwidths. For $73 \mathrm{GHz}, 2 \mathrm{GHz}$ of contiguous bandwidth, which is the widest one of the proposed frequency spectrum, is available for communication [161-163]. The FCC has defined several frequency ranges to be considered as potential candidates; for example, for the frequency range of $24 \mathrm{GHz}$, the $24.25-24.45$ and $25.05-25.25 \mathrm{GHz}$ ranges are the candidate bands. Similarly, for the 28-32 GHz range, the 27.5-28.35, 29.1-29.25, and 31-31.3 GHz ranges are considered. Similarly, for $39 \mathrm{GHz}, 38.6-40$, for 37/42 GHz: 37-38.6 and 42-42.5, for $60 \mathrm{GHz}$ : 57-64 and 64-71, and for 70/80 GHz: 71-76 and 81-86 GHz frequency ranges have been selected [164]. Massive research on the propagation characteristics, implementation, and spectrum, as well as resource management techniques of mmWave band at $28,38,60$, and $73 \mathrm{GHz}$, has been conducted in the last decade. Standard bodies, such as $3 \mathrm{GPP}$ and $5 \mathrm{G}$ channel model, have suggested various channel models below the frequency of $100 \mathrm{GHz}$ (e.g., CI, FI, CIF, and others). Furthermore, by using the data collected by standardization authorities, various firms have performed $5 \mathrm{G}$ field trials. For example, a data rate of $1.2 \mathrm{Gbps}$ is achieved by a mobile user in a $400 \mathrm{MHz}$ channel bandwidth at a $28 \mathrm{GHz}$ frequency band, with a latency of 9-12 ms at $150 \mathrm{~m}$ far from the cell location of AT\&T [165]. A comprehensive study is conducted, and the authors have explicitly mentioned that the mmWave spectrum is suitable for short-range communication and the well-suited propagation model for LOS to receive the desired results [166]. However, in some cases, where LOS propagation is not achievable, NLOS can use the conditions. The path loss and small- and large-scale fading must be addressed to comprehend the propagation 
characteristics of indoor and outdoor locations for wireless communication channels. A study [167] has obtained remarkable results for NLOS mmWave environment by using passive reflectors. Another study [168] is performed for an NLOS indoor localization system by proposing an RF-ECHO method that attains high accuracy in long-distance indoor NLOS environments. The method presents a unique time-of-flight estimation technique to minimize the NLOS constraints. Moreover, it is worth mentioning that these frequency ranges are also suitable to consider as a wireless backhaul link [169]. The major motivation for using these mmWave frequency bands is the possibility of achieving the multi-gigabit wireless communication links. The frequency bands, such as 73 and $76 \mathrm{GHz}$, are also considered as the viable solution for wireless backhaul links $[170,171]$. Several studies show the prominent results for $71-76 \mathrm{GHz}$ and $81-86 \mathrm{GHz}$ frequency bands by utilizing them as a backhaul link $[172,173]$. Besides, the standardization organizations, e.g., ITU, have allocated $81-86 \mathrm{GHz}$ frequency band for high capacity wireless backhaul links [174].

\subsubsection{Above $100 \mathrm{GHz}(100-300 \mathrm{GHz})$}

The availability of large bandwidths at the mmWave band and Terahertz frequencies (frequencies above $100 \mathrm{GHz}$ ) creates the possibility of replacing the end-to-end wire links of indoor and outdoor mobile networks with a wireless system [175]. Currently, the New York University team is considering allotting frequency bands above $100 \mathrm{GHz}$ for licensed and unlicensed wireless communications systems [176]. Considering the fact that only approximately $1177 \mathrm{MHz}$ of the international mobile telecommunications spectrum is currently being utilized, we can anticipate nearly $3-10 \times$ increase in spectrum allocation over the next ten years [177]. The $60 \mathrm{GHz}$ spectrum (between $110 \mathrm{GHz}$ and $170 \mathrm{GHz}$ ) has the potential to be utilized in wireless fixed backhaul links, cellular and vehicular communication, radar, and health monitoring networks. In addition, various frequency spectra are degraded by different atmospheric absorptions. According to the current agreement on spectrum resources in the $60 \mathrm{GHz}$ frequency band, the 120,183, and $325 \mathrm{GHz}$ bands are expected to be applied to provide optimum results for short-distance communication. The reason is that an increase in distance of a couple of meters for large channel bandwidths in this range would be attenuated quickly [178]. With the present need to satisfy user requirements, these frequency ranges are not going to be used in the current $5 \mathrm{G}$ plan; however, they have the potential to deliver high data rates and the ability to support high user demand for future $5 \mathrm{G}$ networks and beyond.

The authors in [179] have reported that the Software-Defined Air-Interface (SDAI) design significantly improves usage efficiency and widens the horizon of spectrum accessibility. The SDAI design is proposed as a design framework for air interface; it involves controller and configurable elements, such as signal processing, coding, and modulation. It can support frequency bands below and above $6 \mathrm{GHz}$ and can utilize the spectrum efficiently to provide full-spectrum service. Moreover, several other features, such as IoT connections, ultralow latency, high data rate, energy efficiency, coverage, and capacity, should be addressed by SDAI. The spectrum accessibility is increased with the help of other fundamental techniques, such as low-density parity-check codes, turbo codes, MIMO, Orthogonal Frequency-Division Multiplexing (OFDM), and other rated techniques [180-182]. Moreover, recent advances in link-level technology in terms of antenna innovations, coupled with the evolving system-level network architecture, are all expected to boost spectrum utilization efficiency in future 6G networks; such advances include the emerging M-MIMO and distributed antenna systems. Besides, MIMO antennas facilitate cooperation among different types of network terminals by allowing opportunistic access $[183,184]$. The utilization of a high band spectrum, such as the mmWave band, is being considered to be the most promising frequency spectrum to fulfill the bandwidth requirements for the next-generation cellular systems [185]. However, the use of the mmWave spectrum leads to disparate fading and signal penetration losses and scattering issues [186]. These problems can be minimized comfortably if the channel properties have been identified earlier before transmitting the signal $[187,188]$. The uncertain behavior of the wireless communication channel has forced many 
researchers to explore different propagation models so that the path loss could be predicted before implementing the methodology in a real-world scenario [189].

The next subsections discuss some recent studies on the high mmWave spectrum band for outdoor and indoor environments.

\subsubsection{Outdoor Investigation}

In [190], the authors have demonstrated a $26 \mathrm{GHz}$ mmWave propagation measurement model for outdoor parking spaces in areas, such as Kuala Lumpur, Malaysia. The research is conducted by implementing a technique of Close-In Free Space (CI) and Floating Intercept (FI) path loss models. Besides, the directional horn and omni antennas are used for Tx (Transmitter) and Rx (Receiver), respectively. They have concluded that the CI model outperforms the FI model. However, a more robust model is required for a moving car scenario. The architects in [191] have focused on the capability of the channel at the mmWave frequency band of $15 \mathrm{GHz}$ by using MIMO technology in outdoor rural and urban environments. Moreover, the Okumura Hata model for rural regions and the microcell path propagation model in urban areas are used as a path loss model to validate the performance. Results have suggested that it is a viable option for future networks because it provides a substantial amount of throughput due to diversified MIMO systems in this frequency band. A study [192] has figured out the free space propagation path loss model for LOS and NLOS environments. It has developed a CI and FI propagation model at various frequency ranges. As a result, the probabilistic path loss model can deliver high bandwidth data rates in mmWave frequency bands, where CI and FI cases show an almost equal output. For a more effective approach, we can apply advanced path loss models, such as Alpha-Beta-Gamma (ABG) and Close-In Frequency Weighting (CIF). The scholars in [193] have analyzed the channel characteristics of the mmWave frequency bands at 28 and $73 \mathrm{GHz}$ and compared the output within the operation of the LTE-A frequency band at $2.14 \mathrm{GHz}$. They have implemented the ABG model and evaluated results in terms of average user throughput and spectral efficiency average cell throughput for various user capacity. Therefore, the results have proved that the mmWave frequency band has a higher overall network performance compared with the $2.14 \mathrm{GHz}$ frequency band of LTE-A. Nonetheless, the interference effect, such as intercell interference, is higher in mmWave, especially for the cell-edge users, due to the signals coming from the adjacent sector of the same cell; cochannel interference also occurs due to the usage of the same frequency in the adjacent. The effect of interference will be analyzed for the multiple-cell scenario for LOS and NLOS environments, thus requiring an efficient methodology to overcome this problem before being implemented in a real-world scenario.

In [194], outdoor propagation parameters are observed with various antenna deployment scenarios at $32 \mathrm{GHz}$ frequency band for LOS and NLOS environments. FI and CI free space path loss models are observed for the outdoor environment. The results have proved that the CI model is more effective than the FI path loss model for NLOS measurement, and cross-polarization increases slower than co-polarization under LOS conditions. Nevertheless, FI shows better performance for the NLOS environment in the horn-horn and horn-omni antenna deployment. For future work, 26, 28, and $38 \mathrm{GHz}$ bands will be inspected under the same environmental conditions. In [195], the investigators have discussed the joint contribution of channel models at $28,38,60$, and $73 \mathrm{GHz}$ and mmWave propagation measurements at four particular scenarios, such as BS-mobile, BS-BS, peer-peer, and V2V. They have applied wideband sliding correlator channel sounder with horn-horn antenna configuration for the outdoor environment. The results have achieved high values of path loss exponent (PLE), whereas a more scrupulous antenna setting is required.

\subsubsection{Indoor Investigation}

The author of [196] has presented single- and multifrequency path loss models to identify the channel behavior at mmWave frequency bands, i.e., 28 and $73 \mathrm{GHz}$, in three typical indoor office layouts. All the measurements are conducted by using a 400 mega chips-per-second broadband 
sliding correlator channel sounder. It has $800 \mathrm{MHz}$ null-to-null RF bandwidth for $48 \mathrm{Tx}-\mathrm{Rx}$ location combinations. Additionally, co-and cross-polarized antenna configurations with LOS and NLOS environments are observed with antenna distance ranging between 3.9 and $45.9 \mathrm{~m}$. Thus, a CI free space path loss model is implemented for single- and multifrequency systems because it provides simplicity and higher network performance without damaging accuracy in comparison with other path loss models, such as FI and ABG. However, the frequency band at $73 \mathrm{GHz}$ is affected by scattering and other penetration losses due to a small wavelength.

In [197], researchers have discussed error performance using different antenna polarization at a $60 \mathrm{GHz}$ frequency band for the LOS environment. It is based on implementing an improvised IEEE 802.15.3c channel model to incorporate with polarization effects and extend it to calculate the error performance of mmWave communication systems that use circular polarization. The result has shown system performance in terms of ray experience and Bit Error Rate (BER) in comparison with linear polarization. The circular polarization in the LOS environment minimizes the multipath effect and, therefore, delivers high performance, specifically when the network operates at high throughput. In [198], the authors have presented mmWave propagation measurement at 28 and $73 \mathrm{GHz}$ for an indoor office environment by using a correlator channel sounder and highly directional horn antennas. RMS delays spread with directional and omnidirectional path loss models; the figures show LOS and NLOS environments for co- and cross-polarized antenna configurations. The authors have concluded that the presented channel models can be utilized for mmWave wireless networks in an indoor environment for current $5 \mathrm{G}$ communication. However, an accurate and more vigorous antenna alignment is required for the LOS environment. The features of indoor propagation channel at four mmWave frequencies $28,39,60$, and $73 \mathrm{GHz}$ are investigated in [199]; propagation signal qualities measured based on building materials are also presented. To validate the behavior of these frequency bands, reliable ray-tracing software is implemented for LOS and NLOS conditions. Results have revealed that as the frequency increases, the received power and delay spread decreases. By contrast, a more robust power optimization method is in demand.

Table 4 shows a summary of the above-discussed latest work for high-spectrum access.

Table 4. Summary of the related work for high-spectrum access.

\begin{tabular}{|c|c|c|c|c|}
\hline Issues/Approach & Methodology/Technique & Advantages & Limitation/Future Work & References \\
\hline \multirow{4}{*}{$\begin{array}{c}\text { Outdoor } \\
\text { investigation }\end{array}$} & $\begin{array}{l}\text { Channel characterization } \\
\text { performed at } 26 \mathrm{GHz} \text { for } \\
\text { tropical outdoor parking } \\
\text { environment by utilizing } \\
\text { Close-In Free Space }(\mathrm{CI}) \text { and } \\
\text { Floating Intercept }(\mathrm{FI}) \text { path } \\
\text { loss model }\end{array}$ & $\begin{array}{l}\text { The CI model } \\
\text { performance is higher } \\
\text { than the FI model }\end{array}$ & $\begin{array}{l}\text { More efficient model is } \\
\text { needed for mobile users }\end{array}$ & [190] \\
\hline & $\begin{array}{l}\text { MIMO channel } \\
\text { characterization at } 15 \mathrm{GHz} \text { for } \\
\text { the outdoor scenario by using } \\
\text { Okumura Hata and } \\
\text { microcell model }\end{array}$ & $\begin{array}{l}\text { Suggested } 15 \mathrm{GHz} \\
\text { band has high data, } \\
\text { which is suitable for } \\
\text { future network }\end{array}$ & Limited bandwidth & [191] \\
\hline & $\begin{array}{l}\text { Propagation characteristics for } \\
28 \text { and } 73 \mathrm{GHz} \text { for the outdoor } \\
\text { environment by using } \mathrm{CI} \text { and } \\
\text { FI propagation model }\end{array}$ & $\begin{array}{l}\text { Higher frequency } \\
\text { spectrum delivers } \\
\text { more data rate }\end{array}$ & $\begin{array}{l}\text { More accurate path loss } \\
\text { model, such as Close-In } \\
\text { Frequency Weighting } \\
(\mathrm{CIF}) \text { and } \\
\text { Alpha-Beta-Gamma } \\
\text { (ABG), can be used }\end{array}$ & [192] \\
\hline & $\begin{array}{l}\text { Propagation characteristics } \\
\text { comparisons of } 28 \text { and } 73 \mathrm{GHz} \\
\text { for the outdoor scenario using } \\
\text { the ABG path loss model }\end{array}$ & $\begin{array}{l}\text { Better throughput and } \\
\text { spectrum efficiency }\end{array}$ & $\begin{array}{l}\text { Signal degrades when } \\
\text { interference increases }\end{array}$ & [193] \\
\hline
\end{tabular}


Table 4. Cont.

\begin{tabular}{|c|c|c|c|c|}
\hline Issues/Approach & Methodology/Technique & Advantages & Limitation/Future Work & References \\
\hline & $\begin{array}{l}\text { Path loss based on directional } \\
\text { and omnidirectional antennas } \\
\text { for } 32 \mathrm{GHz} \text { for both Line of } \\
\text { Sight (LOS) and Non-Line of } \\
\text { Sight (NLOS) } \\
\text { outdoor environment }\end{array}$ & $\begin{array}{l}\text { CI model results are } \\
\text { suitable than the FI } \\
\text { model for } \\
\text { NLOS scenario }\end{array}$ & $\begin{array}{l}\text { A high directional } \\
\text { antenna is needed }\end{array}$ & [194] \\
\hline & $\begin{array}{l}\text { Channel characteristics for } 28 \text {, } \\
38,60 \text {, and } 73 \mathrm{GHz} \text { outdoor } \\
\text { scenarios using a wideband } \\
\text { sliding correlator channel } \\
\text { sounder with the horn-to horn } \\
\text { antenna configuration }\end{array}$ & $\begin{array}{l}\text { Accurate values of } \\
\text { path loss exponent } \\
(\mathrm{PLE}) \text { is achieved }\end{array}$ & $\begin{array}{l}\text { Precise horn antenna } \\
\text { alignment is needed }\end{array}$ & [195] \\
\hline \multirow{4}{*}{$\begin{array}{c}\text { Indoor } \\
\text { investigation }\end{array}$} & $\begin{array}{l}\text { Channel behavior in an indoor } \\
\text { environment for } 28 \text { and } \\
73 \mathrm{GHz} \text { using the CI model }\end{array}$ & $\begin{array}{l}\text { Offer simplicity and } \\
\text { better network } \\
\text { performance }\end{array}$ & $\begin{array}{l}73 \mathrm{GHz} \text { signal suffers } \\
\text { from more } \\
\text { scattering issue }\end{array}$ & [196] \\
\hline & $\begin{array}{l}\text { Polarization effect estimation } \\
\text { for indoor LOS environment } \\
\text { at } 60 \mathrm{GHz} \text { using } \\
\text { ray-tracing simulation }\end{array}$ & $\begin{array}{l}\text { Performance error is } \\
\text { identified }\end{array}$ & $\begin{array}{l}\text { Can enhance the } \\
\text { throughput with } 73 \mathrm{GHz}\end{array}$ & [197] \\
\hline & $\begin{array}{l}\text { Indoor office environment } \\
\text { investigation at } 28 \text { and } 73 \mathrm{GHz} \\
\text { using horn and } \\
\text { omnidirectional antenna in co- } \\
\text { and cross-polarization } \\
\text { antenna settings for both LOS } \\
\text { and NLOS environment }\end{array}$ & $\begin{array}{l}\text { Calculate delay spread } \\
\text { values and determine } \\
\text { the factor of time delay }\end{array}$ & $\begin{array}{l}\text { Precise alignment is } \\
\text { required for } \\
\text { LOS scenario }\end{array}$ & [198] \\
\hline & $\begin{array}{l}\text { Indoor effect of material's } \\
\text { conductivity and permittivity } \\
\text { at } 28,39,60 \text {, and } 73 \mathrm{GHz} \text { for } \\
\text { LOS and NLOS using 3D } \\
\text { ray-tracing wireless } \\
\text { insite software }\end{array}$ & $\begin{array}{l}\text { Amount of received } \\
\text { power and delay } \\
\text { spread decreases along } \\
\text { with the frequency }\end{array}$ & $\begin{array}{l}\text { More efficient power } \\
\text { optimization scheme } \\
\text { is needed }\end{array}$ & [199] \\
\hline
\end{tabular}

\subsection{M-MIMO}

M-MIMO technology has been utilized to maximize system capacity and bitrate since the evolution of LTE-A frameworks $[200,201]$. However, critical work has been conducted in the previous years to help the potential addition of this arrangement of strategies to current 5G networks [202,203]. Different techniques, such as beamforming, Spatial Division Multiple Access (SDMA), and spatial multiplexing, have been utilized in M-MIMO [204-206]. It straightforwardly enhances system throughput and bandwidth efficiency [207]. In contrast to the existing conventional MIMO antenna systems, M-MIMO offers more spectrum and higher power utilization efficiency for the future cellular networks by using the massive array gains provided by the low-complex transmission framework [208]. It is also expected to provide flexibility to avoid interference with the adaptive beamforming technique [209,210].

It is noticed that the performance of MIMO is different for sub-6 GHz and mmWave frequency band. Despite conceptual similarities, the way in which MIMO can be utilized in these bands is fundamentally different due to their transmission behaviors and hardware characteristics. The major differences in M-MIMO design for sub- $6 \mathrm{GHz}$ and mmWave frequencies concern to the propagation mechanisms, transceiver design, and signal processing algorithms [211]. However, the data rate in mmWave frequency band is achieved to be high of around $10 \mathrm{Gbps}$ for a single user, whereas, in sub-6 GHz, around $100 \mathrm{Mbps}$ of data rate can be achieved when using $40 \mathrm{MHz}$ of bandwidth [212]. The use of MIMO in sub- $6 \mathrm{GHz}$ has several advantages over the mmWave frequency band. Like, the beamforming in sub- $6 \mathrm{GHz}$ delivers power-savings and better coverage; however, in mmWave, it is not suitable for low data rate application as it increases the power overhead, especially for IoT and mMTC application [213]. Besides, applications where the requirement of URLLC is necessary, sub-6 GHz M-MIMO improves the network reliability, whereas mmWave M-MIMO faces propagation unreliability due to blockage [214]. 
In order to create communication, two different spectrum utilization techniques can be used, i.e., Time Division Duplex (TDD) and Frequency Division Duplex (FDD). For the mmWave spectrum, M-MIMO is expected to deliver better results in the TDD mode rather than in FDD mode; for sub-6 $\mathrm{GHz}, \mathrm{FDD}$ provides remarkable results $[215,216]$. In the FDD communication mode, the uplink and downlink transmissions usually occur in the same channel simultaneously, thus suppressing a great deal of the spectrum gain, as shown in Figure $6[217,218]$. The FDD is designed for paired uplink/downlink spectrum channel access, which requires two dedicated channels with constant spacing between them. It involves high channel training overhead [219], resulting in linear growth of the channel budget based on the number of the transmit antenna elements. This drawback makes the FDD mode unattractive for M-MIMO system deployment [220]. Meanwhile, the TDD takes advantage of channel reciprocity because the number of transmit antennas used has no direct influence over the channel overhead [221]. In the TDD mode, the aggregation of unlicensed spectrum for downlink and uplink serves the same purpose as in a typical LTE-A TDD CA, which offers the advantage of flexible coordination of resources between the uplink and downlink [222]. Therefore, the M-MIMO system is expected to function in the TDD mode for maximum spectral efficiency for the current 5G networks [223]. Furthermore, when TDD is operated in the $4.5-5 \mathrm{GHz}$ spectrum for radars running service, the transmission must be coordinated through the dynamic frequency selection and transmit power control mechanisms [224,225]. M-MIMO has been considered one of the likely ways to enhance spectrum efficiency [226].

Various issues, such as minimizing BER, spectrum sensing, receiver design, and channel modeling, must be addressed for the design of M-MIMO systems. Several studies have been conducted to explore these areas; a few of them are discussed in the next subsections.

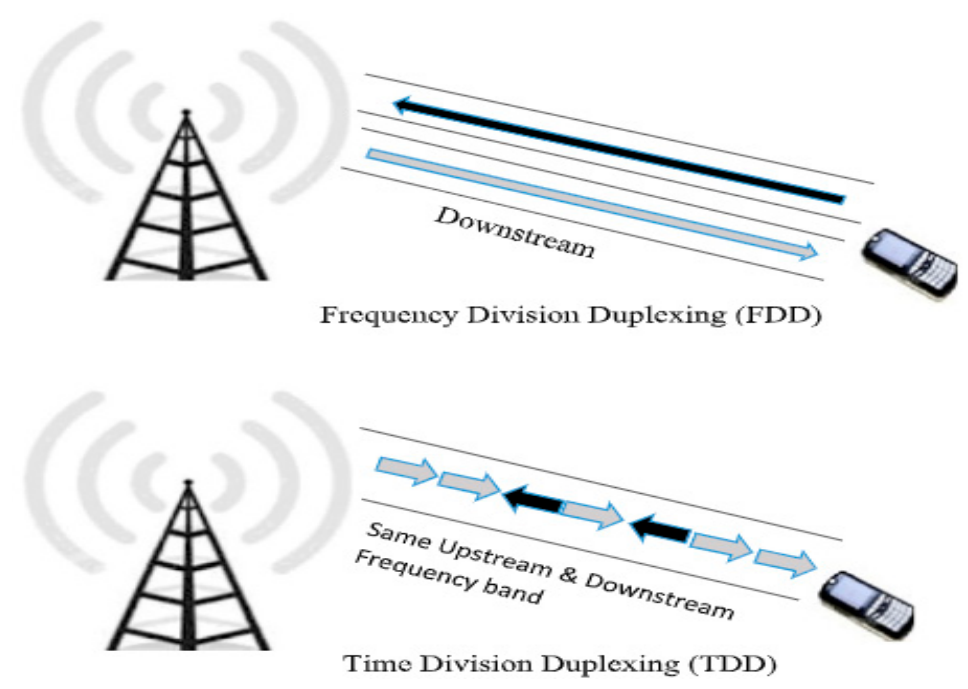

Figure 6. FDD (Frequency Division Duplex) vs. TDD (Time Division Duplex).

\subsubsection{Minimizing BER}

As the future radio 6G demands an extensive array of antenna deployment due to numerous users and its data requirements, a technology that fulfills its desire is M-MIMO. M-MIMO has 20x more antennas than a conventional MIMO system, and traditional methods are complex and inefficient to support the M-MIMO system. In [227], the authors have contributed to the new design of signal detection at BS by the antenna. For this reason, they have suggested a computationally less complex approximate message passing algorithm for the discovery of the M-MIMO system by using MATLAB simulations. Hence, the results are astoundingly amazing as a suggested technique provides a smart and efficient tradeoff between computational complexity and BER performance; moreover, it is less complex for the detection of M-MIMO systems. Furthermore, it can be stretched to large M-MIMO systems with many antennas and users. A study [228] has compared M-MIMO and conventional MIMO 
based on channel parameters. To estimate the channel parameters for traditional and M-MIMO systems, a training-based and blind channel estimation technique is provided and matches the performance of both the systems. Therefore, by implementing the proposed method, M-MIMO delivers a much better BER count than $2 \times 2$ MIMO systems. However, a more agile algorithm is required to simplify the complexities of M-MIMO more.

\subsubsection{Spectrum Sensing}

The authors in [229] have designed a unique compressed sensing framework that differentiates LOS from NLOS signal paths and leads to better performance in comparison with existing approaches. Even though it increases the localization accuracy and minimizes the execution time, a high computational complexity algorithm is found. In [230], the researchers have discussed the importance of throughput and spectral efficiency for higher user services and system performance. The technique called Matched Filter Precoding (MFP) improves the system performance and cell-edge user's throughput in a cooperative M-MIMO network because of an increase in antenna numbers at a BS. Additionally, MFP helps reduce intercell interference among users by using asymptotical orthogonality. Overall, the cooperative M-MIMO mitigates the intercell interference and pilot contamination using many antennas at a BS. However, for a pilot signaling, more comprehensive and refined channel information is required to explore the extensive research work.

\subsubsection{Receivers Design}

As for the M-MIMO system, Huawei and NTT Docomo have conducted massive field trials to evaluate the feasibility of M-MIMO for MU-MIMO schemes for future wireless communication [231]. They have modeled three types of MIMO precoding schemes, such as linear precoding: Eigen Zero-Forcing (EZF), nonlinear precoding: Tomlinson Harashima Precoding (THP), and hybrid precoding. By implementing the methodology, the results have proved that the hybrid scheme brings positive outcomes due to its litheness on selecting EZP and THP to take benefits of both schemes in a practical scenario. The authors in [232] have presented an uplink spectrum efficiency approach for the M-MIMO system. The TDD realization is used based on the Zero-Forcing (ZF) and Maximum Ratio Combining (MRC) schemes. The results have shown that spectral efficiency is significantly improved, and the design condition is dependent on the number of antennas at the BS and pilot reuse factor.

\subsubsection{Channel Modeling}

In [233], the authors have investigated M-MIMO performance in a real propagation channel environment. The channel measurements take on $2.6 \mathrm{GHz}$ with virtual Uniform Linear Array (ULA) and Uniform Cylindrical Array (UCA) in the presence of 128 antenna ports. However, the investigations are held on the Rayleigh channels with theoretical channels and based on measurement data. The channel behavior in three propagation scenarios is discussed, and the results are evaluated. Therefore, the outcomes are achieved for both arrays defined, as the performance is close to that of i.i.d. (independent and identically distributed) Rayleigh fading channels. A study [234] has derived an attainable aggregate rate for time selective channel model for M-MIMO systems. The authors have proved that a major difference is obtained in the sum rate between block fading and time selective models. Moreover, results have shown that for constant amplitude pilots, the asymptotic SINR performance is limited by the effect of interference from the time-selective channel. Additionally, they have suggested that in a block fading, the optimal training is not appropriate for a time-selective channel with ample antenna systems in the BS. However, given numerous antennas and multiuser systems, the signal deteriorates due to interferences, and a constructive and sharp interference cancellation scheme should be investigated. The authors in [235] have discussed the serious concern of pilot contamination in multicell M-MIMO systems under correlated channels. The output is received through simulation via MATLAB, pointing out that if channels are correlated, the performance of M-MIMO degrades massively. They have added that when the channel correlation coefficient is lesser 
than the threshold value, the performance of M-MIMO increases with an increase in the number of antennas. In contrast, for the large channel correlation coefficient, the performance gets better slowly and steadily by increasing the number of BS antennas. The authors in [236] have proposed a scheduling algorithm for the M-MIMO downlink system along with a ZF beamforming approach. The idea is to utilize a channel mean gain and to select a user to achieve maximum sum rate. The results are achieved in terms of error performance, sum rate, throughput, and fairness; however, the authors have suggested that the proposed algorithm must be tested on a realistic model for multiantenna users.

Below is Table 5, which summarizes the techniques, advantages, and limitations of the above-discussed studies.

Table 5. Summary of the related work for M-MIMO.

\begin{tabular}{|c|c|c|c|c|}
\hline Issues/Approach & Methodology/Technique & Advantages & $\begin{array}{c}\text { Limitations/future } \\
\text { Work }\end{array}$ & References \\
\hline \multirow[t]{2}{*}{$\begin{array}{l}\text { Minimizing Better } \\
\text { Bit Error Rate (BER) }\end{array}$} & $\begin{array}{l}\text { MATLAB simulations of } \\
\text { approximate message passing } \\
\text { algorithm for uplink detection }\end{array}$ & $\begin{array}{l}\text { Efficient and less } \\
\text { complicated uplink } \\
\text { detection and the } \\
\text { excellent tradeoff } \\
\text { between complexity } \\
\text { and performance }\end{array}$ & $\begin{array}{l}\text { Can be extended to large } \\
\text { M-MIMO systems with a } \\
\text { vast number of antenna } \\
\text { and users }\end{array}$ & [227] \\
\hline & $\begin{array}{l}\text { Training-based blind channel } \\
\text { estimation techniques }\end{array}$ & BER count & Complex algorithm & {$[228]$} \\
\hline \multirow{2}{*}{ Spectrum Sensing } & $\begin{array}{l}\text { Direct localization algorithm, } \\
\text { which is based on the location } \\
\text { to source for narrowband } \\
\text { multipath }\end{array}$ & $\begin{array}{l}\text { Decreases execution } \\
\text { time and enhances the } \\
\text { spectrum accuracy }\end{array}$ & $\begin{array}{l}\text { Higher computational } \\
\text { complexity }\end{array}$ & [229] \\
\hline & $\begin{array}{l}\text { Performance analysis of } \\
\text { spectral efficiency and BS } \\
\text { antennas using match filter } \\
\text { pre-coding techniques }\end{array}$ & $\begin{array}{l}\text { Improves throughput } \\
\text { and spectral efficiency }\end{array}$ & $\begin{array}{l}\text { More channel } \\
\text { information is needed } \\
\text { for the pilot signal }\end{array}$ & [230] \\
\hline \multirow{2}{*}{ Receiver design } & $\begin{array}{l}\text { Multi-user MIMO precoding } \\
\text { schemes, i.e., Eigen Zero } \\
\text { Forcing (EZF), } \\
\text { Tomlinson-Harashima } \\
\text { Precoding (THP), for different } \\
\text { UE deployment scenarios }\end{array}$ & $\begin{array}{l}\text { Flexibility in a practical } \\
\text { system design }\end{array}$ & $\begin{array}{l}\text { Limited to LOS } \\
\text { environment only }\end{array}$ & [231] \\
\hline & $\begin{array}{l}\text { TDD realization based on Zero } \\
\text { Forcing (ZF) and Maximum } \\
\text { Ratio Combining (MRC) } \\
\text { schemes for uplink } \\
\text { M-MIMO system }\end{array}$ & $\begin{array}{l}\text { Spectral efficiency has } \\
\text { a significant } \\
\text { improvement, and the } \\
\text { design condition is } \\
\text { dependent on the } \\
\text { number of antennas on } \\
\text { the BS and pilot } \\
\text { reuse factor }\end{array}$ & $\begin{array}{l}\text { Limited to a smaller } \\
\text { number of antennas }\end{array}$ & [232] \\
\hline \multirow{4}{*}{ Channel modeling } & $\begin{array}{l}\text { Real measurement has been } \\
\text { performed at } 2.6 \mathrm{GHz} \text { by using } \\
\text { the virtual Uniform Linear } \\
\text { Array (ULA) and Uniform } \\
\text { Cylindrical Array (UCA) }\end{array}$ & $\begin{array}{l}\text { Better performance } \\
\text { close to that in i.i.d. } \\
\text { Rayleigh channels }\end{array}$ & $\begin{array}{l}\text { More transmission } \\
\text { factors, such as } \\
\text { propagation delay, } \\
\text { should be included } \\
\text { in future }\end{array}$ & [233] \\
\hline & $\begin{array}{l}\text { Utilizes first-order } \\
\text { Gauss-Markov Rayleigh } \\
\text { fading channel model in } \\
\text { time-selective channels }\end{array}$ & $\begin{array}{l}\text { Optimum results in the } \\
\text { achieved } \\
\text { aggregate-rate }\end{array}$ & $\begin{array}{l}\text { Interference effect is } \\
\text { not considered }\end{array}$ & [234] \\
\hline & $\begin{array}{l}\text { It has designed an M-MIMO } \\
\text { correlated channel by using } \\
\text { MATLAB simulations to solve } \\
\text { pilot contamination issue }\end{array}$ & $\begin{array}{l}\text { Achieves better } \\
\text { performance by } \\
\text { increasing more } \\
\text { antennas at Base } \\
\text { Station (BS) }\end{array}$ & $\begin{array}{l}\text { Correlated channels } \\
\text { reduce the overall } \\
\text { performance }\end{array}$ & [235] \\
\hline & $\begin{array}{l}\text { A scheduling algorithm based } \\
\text { on the downlink M-MIMO } \\
\text { system along with Zero } \\
\text { Forcing (ZF) } \\
\text { beamforming approach }\end{array}$ & $\begin{array}{l}\text { Better results in terms } \\
\text { of error performance, } \\
\text { sum rate, throughput, } \\
\text { and fairness }\end{array}$ & $\begin{array}{l}\text { Need to test on the more } \\
\text { realistic model and for } \\
\text { multi-antenna users }\end{array}$ & [236] \\
\hline
\end{tabular}




\section{Future Research Challenges}

For future research directions, we present some of the challenges in current $5 \mathrm{G}$ networks that need optimum solutions for designing 6G networks. The future research challenges for the studied topics are summarized as follows:

\subsection{Carrier Aggregation}

An optimal SS framework to allocate multiple resources efficiently among users is crucial for our future SS systems [237]. Multiple CCs across the available spectrum can be utilized to create a wider bandwidth channel to increase the network data throughput and overall capacity [238]. Moreover, an application-aware resource allocation scheme is needed for the users of HetNet to achieve fragmented spectrum allocations and aggregate licensed and unlicensed carrier spectra [239]. A Clear Channel Assessment (CCA) may be performed in response to the uplink grant to determine the availability of an unlicensed spectrum [240]. Moreover, the Licensed Assisted Access (LAA) method is the latest approach presented by 3GPP that can exploit high-spectrum bandwidth to address the limitation of the current 5G network [241]. Various Machine Learning (ML)-based resource allocation techniques can also be applied. For instance, a deep learning method can be used to overcome the resource allocation management of BS by performing fractional spectrum access proactively and selecting the channel dynamically [242]. Lack of dynamic control of wireless network resources leads to unbalanced spectrum loads and introduces capacity bottleneck. Therefore, a solution similar to extended Dynamic Spectrum Access (eDSA) is needed to provide quality load balancing in available spectrum bands, traffic allocation, and capacity enhancement through the aggregation of current resources [243]. Moreover, some AI-based solutions for resource management must be proposed; for example, Evolutionary Programming (EP) algorithm [244].

\subsection{Cognitive Radio}

$\mathrm{CR}$ for spectrum utilization offers the opportunity for flexible spectrum access in the current wireless systems [245]. Spectrum sensing involves the classification of a part of the spectrum or a frequency band as either "occupied" or "unoccupied" [246]. Several types of CR-based schemes are presented recently (e.g., matched filter, energy, and cyclostationary feature detection) [247]. When more accurate information about the primary user is needed, then the best-matched filter is required to perform optimal detection [248]. The cyclostationary approach can also be utilized by using cyclostationary elements of the available spectrum [249]. Moreover, the implementation of cooperative sensing must be performed in a distributed manner; that is, SUs receive information from the neighbors and make a choice on an individual basis [250]. Another way to use the free spectrum efficiently is the utilization of the dynamic genetic algorithm for PUs and SUs [251]. A new promising approach is to utilize ML techniques with CR to improve the spectral and energy efficiency of the network [252]. The handover between the PUs and SUs during resource sharing is a critical task that needs some dynamic handover schemes to achieve high QoS [253]. Moreover, various AI-based approaches are required for effective resource management in CR networks [254]. Although this requires different optimization parameters for different environments, real-time processing can be achieved by combining CR with AI into the Multi-Agent System (MAS), and real-time processing can be achieved [255].

\subsection{Small Cell}

As the use of a high-frequency band in the current $5 \mathrm{G}$ network increases, the utilization of small cell deployment is a mandatory approach to serve a higher number of subscribers [256]. However, the existing spectrum allocation algorithms are insufficient to deliver optimum spectrum allocation efficiency in the small cell network [257]. Therefore, an efficient algorithm, such as K-Nearest Neighbor (KNN) learning algorithm, can be used to classify all the small cells according to their geographic locations and interference radius; thus, the spectrum allocation efficiency can be improved [258]. 
Additionally, for a limited backhaul capacity network, some efficient spectrum allocation solution is required to provide significant performance improvement in throughput enhancement, delay reduction, and energy savings for small-cell networks [259]. The switching between small cells and Wi-Fi remains a challenging task that is being explored in the latest 3GPP releases [260]. Furthermore, in small cell-based HetNet, which consists of multilayers with a shared spectrum, a dynamic spectrum and multicell logarithmic resource allocation algorithm are required [261]. The utilization of various new approaches, such as block-aware power allocation, efficient relay selection, and cooperative caching algorithms, must also be developed to deliver the optimum results for the current $5 \mathrm{G}$ network [262,263]. The BS in HetNet is experiencing a seamless switching between different technologies, such as Wi-Fi and cellular. This continuous switching makes the network suffer from negative parameters, such as intercell interference, SNR, fading, and downstream power. Hence, an optimal solution for resource and power allocation using a feed-forward neural network approach can be implemented for the stability of the network [264]. Similarly, traffic offloading is a critical issue in multitier HetNet; therefore, an autonomous traffic offloading technique based on machine learning is required to reduce transmission delay [265]. Moreover, an efficient design for some new AI-based clustering approach can manage the resource framework while enhancing the efficiency and throughput of the small cell [266]. To improve coverage, AI-based optimization approaches are required, especially for software-defined networking controllers [267].

\subsection{High-Spectrum Access}

The modeling, as well as the measure of high-spectrum channels, play a vital role in guiding toward the complete knowledge of how this spectrum differs from the currently used spectrum [268]. Limited coverage is another big issue for the mmWave spectrum; therefore, detailed stochastic geometric coverage analysis studies with the realistic channel and antenna radiation models are required [269,270]. Moreover, the use of passive reflectors of different shapes and sizes can help enhance the received power, thus improving signal coverage in the NLOS region [271]. Besides, NLOS is assumed to be more important for a lower $6 \mathrm{GHz}$ band rather than in mmWave communication links. On the contrary, high propagation losses and high absorption in mmWave makes the LOS inevitable [272]. However, only a few research studies have focused on designing the channel models for the NLOS scenario to deliver sufficient results $[273,274]$. Although existing channel models provide some insights into the propagation characteristics of mmWave in cellular environments, further research is needed to capture the shades of the propagation and fade in the mmWave scenario [275]. The utilization of clustering in narrow-beam antenna [276] and accurate estimation of departure and arrival angles, as well as the time-of-arrival for each observed radio propagation path, can be used to enhance the overall network performance [277]. Various new frequency spectra, such as 60 and $73 \mathrm{GHz}$ bands, can be studied for various propagation environments and compared with the existing frequency band below $6 \mathrm{GHz}$. Different multifrequency propagation path loss models (in particular, ABG, which is CIF) can be investigated for the evaluation of future high-frequency mmWave networks [278]. Furthermore, some new self-organizing techniques based on ML are required to provide clustering and efficient spectrum allocation for the mmWave system [279]. Moreover, the beam selection for the uplink scenario requires an efficient ML mechanism to deliver a high directional beamforming effect [280]. The AI-based framework can also be used to optimize high-spectrum mmWave compressed sensing for high-speed 5G/6G image transmission [281].

\subsection{M-MIMO}

In mmWave frequency bands, the blockage and path loss phenomena are considerably high. Nonetheless, it can be (partially) surmounted by keeping the structure of antenna array on the basic physical size as it is used in lower frequencies; this can be accomplished by M-MIMO [282]. However, M-MIMO technologies are constructed, implemented, and utilized differently [283]. The main requirements regarding stability, flexibility, and coverage must be investigated for different 
frequency bands, antenna geometries, and propagation environments [284]. Besides, various current precoding schemes have high-computational complexity and fail to maximize spatial information [224]. Conventional digital beamforming involves the complexity of large antenna arrays in addition to the increased cost of the system, whereas analog beamforming can handle only a single data signal at a time. Therefore, various low-cost and less complex hybrid precoding methods are required to model efficient transmitters and testbeds to mitigate jamming for MIMO-based mmWave systems [285-289]. This goal can be achieved by designing architecture with a combination of analog and digital processing that can be utilized to enable beamforming and spatial multiplexing with minimum complexity in achieving optimal performance $[290,291]$. An ML algorithm can be utilized to predict various channel characteristics and create a beamforming M-MIMO dataset framework [292,293]. The AI-and M-MIMO-based systems can deliver good QoS performance for high altitude users [294]. Nonetheless, the explainable AI-controlled based architecture would be useful for several current limitations while performing resource allocation, energy optimization, and minimizing interferences [295].

\section{Conclusions}

The next-generation $6 \mathrm{G}$ wireless network is expected to support essential user applications and increase the efficiency of communication with low latency and high throughput. Advanced SS schemes should be formulated to acquire the full potential of the spectrum for the current $5 \mathrm{G}$ network. Undoubtedly, spectrum management plays a critical role in achieving this goal; however, many issues arise while designing such future networks. Therefore, this study provides a comprehensive review to describe the technologies involved in the current $5 \mathrm{G}$ network design and the issues that occur while performing resource sharing. The five major topics covered in this study are CA, CR, small cell networks, high-spectrum access, and M-MIMO. Several main concepts of each of the approaches with its recent related researches, including the methodologies, advantages, and limitations, are discussed. This study concludes that from the perspective of design and measurement of future 6G networks, the requirement to use different techniques concurrently in the current 5G network could enhance the overall spectral efficiency. We also believe that the future research challenges presented in this study can provide a new perspective for researchers to mitigate spectrum management issues in the design of $6 \mathrm{G}$ wireless networks.

Author Contributions: Conceptualization, F.Q. and M.N.H.; Visualization, M.U.A.S. and M.N.H.; Writing-original draft preparation, F.Q. and M.U.A.S.; Writing-review and editing, F.Q., M.N.H., R.H., and Q.N.N.; Funding acquisition, R.H.; Supervision, R.H. and Q.N.N.; Project administration, Q.N.N. All authors have read and agreed to the published version of the manuscript.

Funding: This paper is supported under the Dana Impak Perdana UKM DIP-2018-040 and Fundamental Research Grant Scheme FRGS/1/2018/TK04/UKM/02/07.

Acknowledgments: The authors would like to acknowledge the support provided by the Network and Communication Technology (NCT) Research Groups, FTSM, UKM in providing facilities throughout this paper. The authors would also like to thank the Editor and the anonymous reviewers for their valuable comments and suggestions.

Conflicts of Interest: The authors declare no conflict of interest.

\section{References}

1. Tsiropoulos, G.I.; Yadav, A.; Zeng, M.; Dobre, O.A. Cooperation in 5G HetNets: Advanced spectrum access and D2D assisted communications. IEEE Wirel. Commun. 2017, 24, 110-117. [CrossRef]

2. Saad, W.; Bennis, M.; Chen, M. A vision of $6 \mathrm{G}$ wireless systems: Applications, trends, technologies, and open research problems. IEEE Netw. 2019. [CrossRef]

3. Mohammed, N.A.; Mansoor, A.M.; Ahmad, R.B. Mission-Critical Machine-Type Communication: An Overview and Perspectives Towards 5G. IEEE Access 2019, 7, 127198-127216. [CrossRef]

4. Faizan, Q. Enhancing QOS Performance of the 5G Network by Characterizing Mm-Wave Channel and Optimizing Interference Cancellation Scheme/Faizan Qamar. Ph.D. Thesis, University of Malaya, Kuala Lumpur, Malaysia, 2019. 
5. Giordani, M.; Polese, M.; Mezzavilla, M.; Rangan, S.; Zorzi, M. Toward 6G networks: Use cases and technologies. IEEE Commun. Mag. 2020, 58, 55-61. [CrossRef]

6. Chen, S.; Liang, Y.-C.; Sun, S.; Kang, S.; Cheng, W.; Peng, M. Vision, requirements, and technology trend of $6 \mathrm{G}$ : How to tackle the challenges of system coverage, capacity, user data-rate and movement speed. IEEE Wirel. Commun. 2020, 27, 218-228. [CrossRef]

7. Han, S.; Chih-Lin, I.; Xie, T.; Wang, S.; Huang, Y.; Dai, L.; Sun, Q.; Cui, C. Achieving High Spectrum Efficiency on High Speed Train for 5G New Radio and Beyond. IEEE Wirel. Commun. 2019, 26, 62-69. [CrossRef]

8. Vinoth, K.; Purushothaman, S.; Baskar, R.; Gomathi, C. Performance Analysis for 5G Wireless Communications Using Massive Mimo Antennas. Int. Res. J. Eng. Technol. 2019, 6, 4387-4395.

9. Polese, M.; Giordani, M.; Zugno, T.; Roy, A.; Goyal, S.; Castor, D.; Zorzi, M. Integrated Access and Backhaul in $5 \mathrm{G}$ mmWave Networks: Potential and Challenges. IEEE Commun. Mag. 2020, 58, 62-68. [CrossRef]

10. Yau, K.-L.A.; Qadir, J.; Wu, C.; Imran, M.A.; Ling, M.H. Cognition-inspired 5G cellular networks: A review and the road ahead. IEEE Access 2018, 6, 35072-35090. [CrossRef]

11. Bogale, T.E.; Le, L.B. Massive MIMO and mmWave for 5G wireless HetNet: Potential benefits and challenges. IEEE Veh. Technol. Mag. 2016, 11, 64-75. [CrossRef]

12. Hindia, M.N.; Qamar, F.; Rahman, T.A.; Amiri, I.S. A stochastic geometrical approach for full-duplex MIMO relaying model of high-density network. Ad Hoc Netw. 2018, 74, 34-46. [CrossRef]

13. Qamar, F.; Dimyati, K.B.; Hindia, M.N.; Noordin, K.A.B.; Al-Samman, A.M. A comprehensive review on coordinated multi-point operation for LTE-A. Comput. Netw. 2017, 123, 19-37. [CrossRef]

14. Dahnil, D.P.; Hassan, R. Wireless Sensor Networks: A framework for community and educational gardens. Adv. Sci. Lett. 2018, 24, 1153-1157. [CrossRef]

15. Tilwari, V.; Hindia, M.N.; Dimyati, K.; Qamar, F.; Talip, A.; Sofian, M. Contention Window and Residual Battery Aware Multipath Routing Schemes in Mobile Ad-hoc Networks. Int. J. Technol. 2019, 10, 1376-1384. [CrossRef]

16. Amiri, I.; Dong, D.S.; Pokhrel, Y.M.; Gachhadar, A.; Maharjan, R.K.; Qamar, F. Resource Tuned Optimal Random Network Coding for Single Hop Multicast future 5G Networks. Int. J. Electron. Telecommun. 2019, 65, 463-469.

17. Li, J.; Lei, G.; Manogaran, G.; Mastorakis, G.; Mavromoustakis, C.X. D2D communication mode selection and resource optimization algorithm with optimal throughput in 5G network. IEEE Access 2019, 7, 25263-25273. [CrossRef]

18. Elijah, O.; Rahman, T.A.; Orikumhi, I.; Leow, C.Y.; Hindia, M.N. An Overview of Internet of Things (IoT) and Data Analytics in Agriculture: Benefits and Challenges. IEEE Internet Things J. 2018, 5, 3758-3773. [CrossRef]

19. Sukjaimuk, R.; Nguyen, Q.N.; Sato, T. A smart congestion control mechanism for the green IoT sensor-enabled information-centric networking. Sensors 2018, 18, 2889. [CrossRef]

20. Udeshi, D.; Qamar, F. Quality Analysis of Epon Network for Uplink and Downlink Design. Asian J. Eng. Sci. Technol. 2014, 4, 78-83.

21. Gachhadar, A.; Qamar, F.; Dong, D.S.; Majed, M.B.; Hanafi, E.; Amiri, I.S. Traffic Offloading in 5G Heterogeneous Networks using Rank based Network Selection. J. Eng. Sci. Technol. Rev. 2019, 12. [CrossRef]

22. Hashem, I.A.T.; Yaqoob, I.; Anuar, N.B.; Mokhtar, S.; Gani, A.; Khan, S.U. The rise of "big data" on cloud computing: Review and open research issues. Inf. Syst. 2015, 47, 98-115. [CrossRef]

23. Gachhadar, A.; Hindia, M.N.; Qamar, F.; Siddiqui, M.H.S.; Noordin, K.A.; Amiri, I.S. Modified genetic algorithm based power allocation scheme for amplify-and-forward cooperative relay network. Comput. Electr. Eng. 2018, 69, 628-641. [CrossRef]

24. Noordin, K.A.B.; Hindia, M.N.; Qamar, F.; Dimyati, K. Power Allocation Scheme Using PSO for Amplify and Forward Cooperative Relaying Network. In Science and information conference; Arai, K., Kapoor, S., Bhatia, R., Eds.; Springer: Cham, Switzerland, 2018; pp. 636-647.

25. Hassan, R.; Aman, A.H.M.; Latiff, L.A. Framework for Handover process using Visible Light Communications in 5G. In Proceedings of the 2019 Symposium on Future Telecommunication Technologies (SOFTT), Kuala Lumpur, Malaysia, 18-19 November 2019; pp. 1-4.

26. Hindia, M.N.; Qamar, F.; Abbas, T.; Dimyati, K.; Abu Talip, M.S.; Amiri, I.S. Interference cancelation for high-density fifth-generation relaying network using stochastic geometrical approach. Int. J. Distrib. Sens. Netw. 2019, 15, 1550147719855879. [CrossRef] 
27. SAIZAN, Z.; SINGH, D. Cyber security awareness among social media users: Case study in German-Malaysian Institute (GMI). Asia-Pac. J. Inform. Technol. Multimed. 2018, 7, 111-127. [CrossRef]

28. Muniyandi, R.C.; Qamar, F.; Jasim, A.N. Genetic Optimized Location Aided Routing Protocol for VANET Based on Rectangular Estimation of Position. Appl. Sci. 2020, 10, 5759. [CrossRef]

29. Mamode, M.I.S.; Fowdur, T.P. Survey of Scheduling Schemes in 5G Mobile Communication Systems. J. Electr. Eng. Electron. Control Comput. Sci. 2020, 6, 21-30.

30. Giordani, M.; Zorzi, M. Satellite communication at millimeter waves: A key enabler of the 6G era. In Proceedings of the 2020 International Conference on Computing, Networking and Communications (ICNC), Big Island, HI, USA, 17-20 February 2020; pp. 383-388.

31. Letaief, K.B.; Chen, W.; Shi, Y.; Zhang, J.; Zhang, Y.-J.A. The roadmap to 6G: AI empowered wireless networks. IEEE Commun. Mag. 2019, 57, 84-90. [CrossRef]

32. Jameel, F.; Sharma, N.; Khan, M.A.; Khan, I.; Alam, M.M.; Mastorakis, G.; Mavromoustakis, C.X. Machine learning techniques for wireless-powered ambient backscatter communications: Enabling intelligent IoT networks in 6G era. In Convergence of Artificial Intelligence and the Internet of Things; Springer: Cham, Switzerland, 2020; pp. 187-211.

33. Kato, N.; Mao, B.; Tang, F.; Kawamoto, Y.; Liu, J. Ten Challenges in Advancing Machine Learning Technologies toward 6G. IEEE Wirel. Commun. 2020. [CrossRef]

34. Hewa, T.; Gür, G.; Kalla, A.; Ylianttila, M.; Bracken, A.; Liyanage, M. The Role of Blockchain in 6G: Challenges, Opportunities and Research Directions. In Proceedings of the 2020 2nd 6G Wireless Summit (6G SUMMIT), Levi, Finland, 17-20 March 2020; pp. 1-5.

35. Liu, Y.; Yuan, X.; Xiong, Z.; Kang, J.; Wang, X.; Niyato, D. Federated Learning for 6G Communications: Challenges, Methods, and Future Directions. arXiv 2020, arXiv:2006.02931.

36. Ansari, R.I.; Pervaiz, H.; Hassan, S.A.; Chrysostomou, C.; Imran, M.A.; Mumtaz, S.; Tafazolli, R. A new dimension to spectrum management in iot empowered 5G networks. IEEE Netw. 2019, 33, 186-193. [CrossRef]

37. Lopez, A.V.; Chervyakov, A.; Chance, G.; Verma, S.; Tang, Y. Opportunities and Challenges of mmWave NR. IEEE Wirel. Commun. 2019, 26, 4-6. [CrossRef]

38. Papadias, C.B.; Ratnarajah, T.; Slock, D.T. The Future Outlook for Spectrum Sharing. In Spectrum Sharing: The Next Frontier in Wireless Networks; Wiley-IEEE Press: New Jersey, NJ, USA, 2019; pp. 389-404.

39. Hudson, H. 5G Mobile Broadband: Spectrum Challenges for Rural Regions. SSRN 2019. [CrossRef]

40. Kokkinen, T.; Kokkinen, H.; Yrjölä, S. Location dependent spectrum valuation of private LTE and 5G networks in Europe. In Proceedings of the International Conference on Cognitive Radio Oriented Wireless Networks, Poznan, Poland, 11-12 June 2019; pp. 306-319.

41. Chandramouli, D.; Liebhart, R.; Pirskanen, J. Wireless Spectrum for 5G. In 5G for the Connected World; Chandramouli, D., Liebhart, R., Pirskanen, J., Eds.; Wiley Telecom: New Jersey, NJ, USA, 2019; pp. 35-50.

42. Frieden, $\mathrm{R}$. The evolving $5 \mathrm{G}$ case study in spectrum management and industrial policy. Telecommun. Policy 2019, 43, 549-562. [CrossRef]

43. Mekuria, F.; Mfupe, L. Spectrum Sharing for Unlicensed 5G Networks. In Proceedings of the 2019 IEEE Wireless Communications and Networking Conference (WCNC), Marrakech, Morocco, 15-19 April 2019; pp. 1-5.

44. Ksentini, A.; Frangoudis, P.A. Toward Slicing-Enabled Multi-Access Edge Computing in 5G. IEEE Netw. 2020, 34, 99-105. [CrossRef]

45. Frieden, $\mathrm{R}$. The evolving $5 \mathrm{G}$ case study in United States unilateral spectrum planning and policy. Telecommun. Policy 2020, 44, 102011. [CrossRef]

46. Zhang, G.; Zhang, H.; Han, Z.; Karagiannidis, G.K. Spectrum allocation and power control in full-duplex ultra-dense heterogeneous networks. IEEE Trans. Commun. 2019, 67, 4365-4380. [CrossRef]

47. Raeespour, A.K.; Patel, A.M. Design and Evaluation of a Virtual Private Network Architecture for Collaborating Specialist Users. Asia-Pac. J. Inf. Technol. Multimed. 2016, 5. [CrossRef]

48. Shamim, H.; Zhang, H.; Moussa, C.; Liu, K. Effective capacity-aware resource allocation for 5G ultra dense network with hybrid access mode. In Proceedings of the the Conference on Research in Adaptive and Convergent Systems, Chongqing, China, 24-27 September 2019; pp. 224-229.

49. Imran, M.A.; Zhang, Y.; Lee, I.; Zhang, X.; Da Costa, D.B.; Imran, A. IEEE Access Special Section: Deployment and Management of Small Heterogeneous Cells for 5G. IEEE Access 2020, 8, 19406-19409. [CrossRef] 
50. Xu, Y.; Gui, G.; Li, G.; Liu, M.; Gacanin, H.; Adachi, F. A Survey on Resource Allocation for 5G Heterogeneous Networks: Current Research, Future Trends and Challenges. TechRxiv 2020. [CrossRef]

51. Alliance, N. Small Cell Cost Sharing-Full Report. Available online: https://www.ngmn.org/wpcontent/uploads/Publications/2020/Small-cell-economics-external-full-report-v1_1-clean.pdf (accessed on 2 December 2019).

52. Patchala, S.; Sailaja, M. Improvement Spectral Efficiency in mmWave MIMO system for 5 G communications. In Proceedings of the 2019 3rd International Conference on Computing Methodologies and Communication (ICCMC), Erode, India, 27-29 March 2019; pp. 540-544.

53. Kour, H.; Jha, R.K. Power Optimization using Spectrum Sharing for 5G Wireless Networks. In Proceedings of the 2019 11th International Conference on Communication Systems \& Networks (COMSNETS), Bengaluru, India, 7-11 January 2019; pp. 395-398.

54. Buzzi, S.; D'Andrea, C.; Zappone, A.; D'Elia, C. User-centric 5G cellular networks: Resource allocation and comparison with the cell-free massive MIMO approach. IEEE Trans. Wirel. Commun. 2019. [CrossRef]

55. Stepanets, I.; Fokin, G.; Müller, A. Beamforming Techniques Performance Evaluation for 5G Massive MIMO Systems. In Proceedings of the Central Europe Regional Contest (CERC), Darmstadt, Germany, 29-30 March 2019; pp. 57-68.

56. Hefnawi, M. Hybrid beamforming for millimeter-wave heterogeneous networks. Electronics 2019, 8, 133. [CrossRef]

57. Björnson, E.; Sanguinetti, L.; Wymeersch, H.; Hoydis, J.; Marzetta, T.L. Massive MIMO is a reality-What is next?: Five promising research directions for antenna arrays. Digit. Signal Process. 2019, 94, 3-20. [CrossRef]

58. Malathy, S.; Porkodi, V.; Sampathkumar, A.; Hindia, M.N.; Dimyati, K.; Tilwari, V.; Qamar, F.; Amiri, I.S. An optimal network coding based backpressure routing approach for massive IoT network. Wirel. Netw. 2020, 26, 3657-3674. [CrossRef]

59. Mohd Zaki, I.; Rosilah, H. The Implementation of Internet of Things using Test Bed in the UKMnet Environment. Asia-Pac. J. Inf. Technol. Multimed. 2019, 8. [CrossRef]

60. Flamini, R.; Mazzucco, C.; Lombardi, R.; Massagrande, C.; Morgia, F.; Milani, A. Millimeter-wave phased arrays for 5G: An industry view on current issues and challenges. In Proceedings of the 2019 IEEE International Symposium on Phased Array System \& Technology (PAST), Waltham, MA, USA, 15-18 October 2019; pp. 1-2.

61. Taheribakhsh, M.; Jafari, A.; Peiro, M.M.; Kazemifard, N. 5G Implementation: Major Issues and Challenges. In Proceedings of the 2020 25th International Computer Conference, Computer Society of Iran (CSICC), Tehran, Iran, 1-2 January 2020; pp. 1-5.

62. Huang, P.-H.; Psounis, K. Optimal backhauling for dense small-cell deployments using mmWave links. Comput. Commun. 2019, 138, 32-44. [CrossRef]

63. Gupta, A.; Jha, R.K. A survey of 5G network: Architecture and emerging technologies. IEEE Access 2015, 3, 1206-1232. [CrossRef]

64. Niu, Y.; Li, Y.; Jin, D.; Su, L.; Vasilakos, A.V. A survey of millimeter wave communications (mmWave) for 5G: Opportunities and challenges. Wirel. Netw. 2015, 21, 2657-2676. [CrossRef]

65. Atarashi, H.; Iwamura, M.; Nagata, S.; Nakamura, T.; Toskala, A. 5 G Targets and Standardization. In 5 G Technology: 3 GPP New Radio; Holma, H., Toskala, A., Nakamura, T., Eds.; Wiley: New Jersey, NJ, USA, 2019; pp. 13-25.

66. Commission, F.C. Fact sheet: Spectrum frontiers rules identify, open up vast amounts of new high-band spectrum for next generation (5G) wireless broadband. Online 2016, 7, 14.

67. Kurose, T.; Kishimoto, S.; Kim, M. Comparison of angle-of-arrival characteristics at $2.4 \mathrm{GHz}$ and $60 \mathrm{GHz}$ bands. IEICE Commun. Express 2019, 8, 404-409. [CrossRef]

68. Yajun, Z.; Guanghui, Y.; Hanqing, X. 6G mobile communication networks: Vision, challenges, and key technologies. Sci. Sin. Inf. 2019, 49, 963-987.

69. Zhang, Z.; Xiao, Y.; Ma, Z.; Xiao, M.; Ding, Z.; Lei, X.; Karagiannidis, G.K.; Fan, P. 6G wireless networks: Vision, requirements, architecture, and key technologies. IEEE Veh. Technol. Mag. 2019, 14, 28-41. [CrossRef]

70. Khan, L.U.; Yaqoob, I.; Imran, M.; Han, Z.; Hong, C.S. 6G Wireless Systems: A Vision, Architectural Elements, and Future Directions. IEEE Access 2020, 8, 147029-147044. [CrossRef] 
71. Ahmed, R.; Malviya, A.K.; Kaur, M.J.; Mishra, V.P. Comprehensive Survey of Key Technologies Enabling 5G-IoT. In Proceedings of the 2nd International Conference on Advanced Computing and Software Engineering (ICACSE), Sultanpur, India, 8-9 February 2019.

72. Kazmi, S.A.; Khan, L.U.; Tran, N.H.; Hong, C.S. 5G Networks. In Network Slicing for 5 G and Beyond Networks; Springer: Berlin/Heidelberg, Germany, 2019; pp. 1-12.

73. Viswanathan, H.; Mogensen, P.E. Communications in the 6G era. IEEE Access 2020, 8, 57063-57074. [CrossRef]

74. Shafi, M.; Molisch, A.F.; Smith, P.J.; Haustein, T.; Zhu, P.; De Silva, P.; Tufvesson, F.; Benjebbour, A.; Wunder, G. 5G: A tutorial overview of standards, trials, challenges, deployment, and practice. IEEE J. Sel. Areas Commun. 2017, 35, 1201-1221. [CrossRef]

75. Matinmikko-Blue, M.; Yrjölä, S.; Ahokangas, P. Spectrum Management in the 6G Era: The Role of Regulation and Spectrum Sharing. In Proceedings of the 2020 2nd 6G Wireless Summit (6G SUMMIT), Levi, Finland, 17-20 March 2020; pp. 1-5.

76. Parkvall, S.; Dahlman, E.; Furuskar, A.; Frenne, M. NR: The new 5G radio access technology. IEEE Commun. Stand. Mag. 2017, 1, 24-30. [CrossRef]

77. Dahlman, E.; Parkvall, S.; Skold, J. 5G NR: The Next Generation Wireless Access Technology; Academic Press: Cambridge, MA, USA, 2018.

78. Dehghani, M.; Arshad, K.; MacKenzie, R. LTE-Advanced radio access enhancements: A survey. Wirel. Pers. Commun. 2015, 80, 891-921. [CrossRef]

79. Alam, M.J.; Ma, M. Resource matching in carrier aggregation enabling 5G networks. Wirel. Pers. Commun. 2017, 95, 1229-1248. [CrossRef]

80. Taleb, T. Toward carrier cloud: Potential, challenges, and solutions. IEEE Wirel. Commun. 2014, $21,80-91$. [CrossRef]

81. Goyal, A.; Kumar, K. LTE-Advanced Carrier Aggregation for Enhancement of Bandwidth. In Advances in VLSI, Communication, and Signal Processing; Springer: Singapore, 2020; pp. 341-351.

82. Padmapriya, T.; Saminadan, V. QoE based carrier aggregation techniques in LTE-Advanced networks. In Proceedings of the 2017 International Conference on Intelligent Sustainable Systems (ICISS), Tirupur, India, 7-8 December 2017; pp. 811-815.

83. Lun, J.; Frenger, P.; Furuskar, A.; Trojer, E. 5G New Radio for Rural Broadband: How to Achieve Long-Range Coverage on the $3.5 \mathrm{GHz}$ Band. In Proceedings of the 2019 IEEE 90th Vehicular Technology Conference (VTC2019-Fall), Honolulu, HI, USA, 22-25 September 2019; pp. 1-6.

84. Jinaporn, N.; Armour, S.; Doufexi, A. Performance Evaluation on Resource Allocation with Carrier Aggregation in LTE Cellular Networks. In Proceedings of the 2019 IEEE 90th Vehicular Technology Conference (VTC2019-Fall), Honolulu, HI, USA, 22-25 September; pp. 1-5.

85. Rohmah, Y.S.; Hadiyoso, S.; Prasetya, B. LTE-Advanced Network Planning Using Inter-band Non-Contiguous Carrier Aggregation Technology at Soreang-Pasir Koja Highway. In Proceedings of the 2019 International Conference on Information and Communications Technology (ICOIACT), Yogyakarta, Indonesia, 24-25 July 2019; pp. 276-280.

86. Kumar, G.; Saini, G. Implementation of Fractional Frequency Reuse Schemes in LTE-A Network. In Proceedings of the 2nd International Conference on Communication, Computing and Networking; Krishna, C., Dutta, M., Kumar, R., Eds.; Springer: Singapore, 2019; pp. 313-321.

87. Regev, D.; Shilo, S.; Ezri, D.; Zhang, J. A Robust Reconfigurable Front-End for Non-contiguous Multi-Channel Carrier Aggregation Receivers. In Proceedings of the 2018 IEEE Radio Frequency Integrated Circuits Symposium (RFIC), Philadelphia, PA, USA, 10-12 June 2018; pp. 8-11.

88. Lee, H.; Vahid, S.; Moessner, K. A survey of radio resource management for spectrum aggregation in LTE-advanced. IEEE Commun. Surv. Tutor. 2014, 16, 745-760. [CrossRef]

89. Hamza, E.E.A. Optimization of $4 \mathrm{G}$ by Advanced Carrier Aggregation Strategies. Master's Thesis, Sudan University of Science and Technology, Khartoum, Sudan, 2018.

90. Sasikumar, S.; Jayakumari, J. Spectral Efficiency-Energy Efficiency Tradeoff Analysis for a Carrier Aggregated 5G NR Based System. In Advances in Communication Systems and Networks; Jayakumari, J., Karagiannidis, G., Ma, M., Hossain, S., Eds.; Springer: Singapore, 2020; pp. 45-55.

91. Chayon, H.R.; Dimyati, K.; Ramiah, H.; Reza, A.W. An Improved Radio Resource Management with Carrier Aggregation in LTE Advanced. Appl. Sci. 2017, 7, 394. [CrossRef] 
92. Chung, Y.-L. A novel algorithm for efficient downlink packet scheduling for multiple-component-carrier cellular systems. Energies 2016, 9, 950. [CrossRef]

93. Gao, W.; Ma, L.; Chuai, G. Joint optimization of component carrier selection and resource allocation in 5G carrier aggregation system. Phys. Commun. 2017, 25, 293-297. [CrossRef]

94. Al Katsha, M.Z.; Ramli, H.A.M. Development of a novel component carrier selection algorithm in Long Term Evolution-Advanced (LTE-A) with Carrier Aggregation. In Proceedings of the 2016 IEEE Student Conference on Research and Development (SCOReD), Kuala Lumpur, Malaysia, 13-14 December 2016; pp. 1-5.

95. James, A.; Madhukumar, A. Enhanced coverage through relay assisted carrier aggregation for cellular networks. Digit. Signal Process. 2017, 65, 52-62. [CrossRef]

96. Chavarria-Reyes, E.; Akyildiz, I.F.; Fadel, E. Energy-efficient multi-stream carrier aggregation for heterogeneous networks in 5G wireless systems. IEEE Trans. Wirel. Commun. 2016, 15, 7432-7443. [CrossRef]

97. Zhang, J.; Meng, L.; Ji, H. Joint cell association and user scheduling in carrier aggregated heterogeneous networks. Information 2018, 9, 9. [CrossRef]

98. Chang, B.-J.; Feng, S.-T.; Jhuang, K.-P. Adaptive Carrier Aggregation with Differentiating Cloud Services for Maximizing Radio Resource Efficiency and Reward Toward 5G Cellular Network. Wirel. Pers. Commun. 2019, 105, 1401-1433. [CrossRef]

99. Kim, J.; Ku, B.-H.; Lee, S.; Kim, S.; Ryu, K. High Performance Receiver Design for RX Carrier Aggregation. J. Low Power Electron. Appl. 2017, 7, 9. [CrossRef]

100. Tu, Y.; Yang, Z.; Fu, S.; Qin, Y. Latency-efficient code-division multiplexing (CDM) based carrier aggregation for 5G NR mobile fronthaul. Opt. Commun. 2020, 472, 126051. [CrossRef]

101. Salem, T.M. The State of the Art in Cognitive Radio Networks in 5G Hetergeneous Networks. In Fundamental and Supportive Technologies for 5G Mobile Networks; IGI Global: Hershey, PA, USA, 2020; pp. 213-253.

102. Islam, M.N.H.; Rashid, M.M.; Asaduzzaman, A.; Hossain, M.S.; Hossain, M.A. Analysis and Application of Cognitive Radio on 4G Communications. J. Commun. Eng. Syst. 2019, 4, 1-8.

103. Hindia, M.N.; Qamar, F.; Ojukwu, H.; Dimyati, K.; Al-Samman, A.M.; Amiri, I.S. On Platform to Enable the Cognitive Radio Over 5G Networks. Wirel. Pers. Commun. 2020, 113, 1241-1262. [CrossRef]

104. Haldorai, A.; Kandaswamy, U. Cooperative spectrum handovers in cognitive radio networks. In Intelligent Spectrum Handovers in Cognitive Radio Networks; Springer International Publishing: Cham, Switzerland, 2019; pp. 1-18. [CrossRef]

105. Kumar, K.; Prakash, A.; Tripathi, R. Spectrum handoff in cognitive radio networks: A classification and comprehensive survey. J. Netw. Comput. Appl. 2016, 61, 161-188. [CrossRef]

106. Ali, A.; Hamouda, W. Advances on spectrum sensing for cognitive radio networks: Theory and applications. IEEE Commun. Surv. Tutor. 2016, 19, 1277-1304. [CrossRef]

107. He, Y.; Yin, H.; Zhao, N. Multiuser-diversity-based interference alignment in cognitive radio networks. AEU-Int. J. Electron. Commun. 2016, 70, 617-628. [CrossRef]

108. Jiang, C.; Zhang, H.; Ren, Y.; Han, Z.; Chen, K.-C.; Hanzo, L. Machine learning paradigms for next-generation wireless networks. IEEE Wirel. Commun. 2017, 24, 98-105. [CrossRef]

109. Hasan, N.U.; Ejaz, W.; Ejaz, N.; Kim, H.S.; Anpalagan, A.; Jo, M. Network selection and channel allocation for spectrum sharing in $5 \mathrm{G}$ heterogeneous networks. IEEE Access 2016, 4, 980-992. [CrossRef]

110. Hindia, M.N.; Qamar, F.; Majed, M.B.; Rahman, T.A.; Amiri, I.S. Enabling remote-control for the power sub-stations over LTE-A networks. Telecommun. Syst. 2018, 70, 37-53. [CrossRef]

111. Ahmad, W.; Radzi, N.; Samidi, F.; Ismail, A.; Abdullah, F.; Jamaludin, M.; Zakaria, M. 5G technology: Towards dynamic spectrum sharing using cognitive radio networks. IEEE Access 2020, 8, 14460-14488. [CrossRef]

112. Learned, R.E. Cognitive Radio Method and Apparatus for Achieving ad Hoc Interference Multiple Access Wireless Communication. U.S. Patent 10,299,281, 21 May 2019.

113. Bhandari, S.; Bhandari, M.; Joshi, S. Spectrum Sharing in Cognitive Radio Networks for 5G Vision. In Proceedings of the 2019 2th International Conference on Advanced Computational and Communication Paradigms (ICACCP), Gangtok, India, 25-28 February 2019; pp. 1-6.

114. Buzzi, S.; Chih-Lin, I.; Klein, T.E.; Poor, H.V.; Yang, C.; Zappone, A. A survey of energy-efficient techniques for 5G networks and challenges ahead. IEEE J. Sel. Areas Commun. 2016, 34, 697-709. [CrossRef] 
115. Cabric, D.; Brodersen, R.W. Cognitive radio spectrum sharing technology. Wirel. Technol. Circuits Syst. Devices 2017, 4, 131-157.

116. Sheikh, J.A.; Mir, Z.I.; Parah, S.A.; Bhat, G.M. A New Filter Bank Multicarrier (FBMC) Based Cognitive Radio for 5 G Networks Using Optimization Techniques. Wirel. Pers. Commun. 2020, 112, 1265-1280. [CrossRef]

117. Prasad, R.G.; Venkatesan, P. Group Based Multi-Channel Synchronized Spectrum Sensing in Cognitive Radio Network with 5G. Mob. Netw. Appl. 2019, 24, 327-339. [CrossRef]

118. Zhu, S.; Wang, J.; Li, W.W. Optimal Service Rate in Cognitive Radio Networks with Different Queue Length Information. IEEE Access 2018. [CrossRef]

119. Guirguis, A.; Karmoose, M.; Habak, K.; El-Nainay, M.; Youssef, M. Cooperation-based multi-hop routing protocol for cognitive radio networks. J. Netw. Comput. Appl. 2018, 110, 27-42. [CrossRef]

120. Tegou, T.I.; Tsiflikiotis, A.; Vergados, D.D.; Siakavara, K.; Nikolaidis, S.; Goudos, S.K.; Sarigiannidis, P.; Obaidat, M. Spectrum allocation in cognitive radio networks using chaotic biogeography-based optimisation. IET Netw. 2018, 7, 328-335. [CrossRef]

121. Aslam, S.; Jang, J.; Lee, K.-G. Unified Channel Management for Cognitive Radio Sensor Networks Aided Internet of Things. Sensors 2018, 18, 2665. [CrossRef]

122. Miao, L. Research of Snr Estimation and Prediction Method Used in Cognitive Radio. Procedia Comput. Sci. 2018, 131, 1164-1169. [CrossRef]

123. Lv, H.; Li, P.; Yan, Q.; Zhang, H. Energy-efficient multi-cell resource allocation in cognitive radio-enabled 5G systems. EURASIP J. Adv. Signal Process. 2019, 2019, 4. [CrossRef]

124. Kumar, S.; Singh, A.K. A localized algorithm for clustering in cognitive radio networks. J. King Saud Univ.-Comput. Inf. Sci. 2018. [CrossRef]

125. Idoudi, H.; Mabrouk, O.; Minet, P.; Saidane, L.A. Cluster-based scheduling for cognitive radio sensor networks. J. Ambient Intell. Humaniz. Comput. 2019, 10, 477-489. [CrossRef]

126. Athanasiadou, G.E.; Fytampanis, P.; Zarbouti, D.A.; Tsoulos, G.V.; Gkonis, P.K.; Kaklamani, D.I. Radio network planning towards 5G mmWave standalone small-cell architectures. Electronics 2020, 9, 339. [CrossRef]

127. Manap, S.; Dimyati, K.; Hindia, M.N.; Talip, M.S.A.; Tafazolli, R. Survey of Radio Resource Management in 5G Heterogeneous Networks. IEEE Access 2020, 8, 131202-131223. [CrossRef]

128. Andrews, J.G.; Zhang, X.; Durgin, G.D.; Gupta, A.K. Are we approaching the fundamental limits of wireless network densification? IEEE Commun. Mag. 2016, 54, 184-190. [CrossRef]

129. Bhandari, N.; Devra, S.; Singh, K. Evolution of Cellular Network: From 1G to 5G. Int. J. Eng. Tech. 2017, 3, 98-105.

130. Turkmen, A.; Mollel, M.S.; Ozturk, M.; Yao, S.; Zhang, L.; Ghannam, R.; Imran, M.A. Coverage analysis for indoor-outdoor coexistence for millimetre-wave communication. In Proceedings of the 2019 UK/China Emerging Technologies (UCET), Glasgow, UK, 21-22 August 2019; pp. 1-4.

131. Saha, C.; Afshang, M.; Dhillon, H.S. Enriched \$ K \$-tier HetNet model to enable the analysis of user-centric small cell deployments. IEEE Trans. Wirel. Commun. 2017, 16, 1593-1608. [CrossRef]

132. Atat, R.; Bradley, R.S.; Serpedin, E. Toward Solar Energy Harvesting for Small Cell Networks: Technology, Feasibility, and Challenges. In Proceedings of the 2019 5th Experiment International Conference (exp. at'19), Funchal, Portugal, 12-14 June 2019; pp. 90-95.

133. Claussen, H.; Lopez-Perez, D.; Ho, L.; Razavi, R.; Kucera, S. Small Cell Networks: Deployment, Management, and Optimization; John Wiley \& Sons: Hoboken, NJ, USA, 2017.

134. Qamar, F.; Hindia, M.N.; Dimyati, K.; Noordin, K.A.; Amiri, I.S. Interference management issues for the future 5G network: A review. Telecommun. Syst. 2019, 71, 627-643. [CrossRef]

135. Qamar, F.; Dimyati, K.; Hindia, M.N.; Noordin, K.A.; Amiri, I.S. A stochastically geometrical poisson point process approach for the future 5G D2D enabled cooperative cellular network. IEEE Access 2019, 7, 60465-60485. [CrossRef]

136. Alsharif, M.H.; Nordin, R.; Shakir, M.M.; Ramly, A.M. Small Cells Integration with the Macro-Cell Under LTE Cellular Networks and Potential Extension for 5G. J. Electr. Eng. Technol. 2019, 14, 2455-2465. [CrossRef]

137. Kouchaki, M.R.; Dabibi, M. Experiment on High Capacity Backhaul Transmission Link Aggregation Solution for 5G Networks. In Proceedings of the 2020 26th Conference of Open Innovations Association (FRUCT), Yaroslavl, Russia, 20-24 April 2020; pp. 1-6.

138. Pratap, A.; Misra, R.; Das, S.K. Maximizing Fairness for Resource Allocation in Heterogeneous 5 G Networks. IEEE Trans. Mob. Comput. 2019. [CrossRef] 
139. Arévalo, G.V.; Gaudino, R. Optimal dimensioning of the $5 \mathrm{G}$ optical fronthaulings for providing ultra-high bit rates in small-cell, micro-cell and femto-cell deployments. In Proceedings of the 2019 21st International Conference on Transparent Optical Networks (ICTON), Angers, France, 9-13 July 2019; pp. 1-4.

140. Chen, J.; Ge, X.; Ni, Q. Coverage and handoff analysis of 5G fractal small cell networks. IEEE Trans. Wirel. Commun. 2019, 18, 1263-1276. [CrossRef]

141. Saha, R.K. A technique for massive spectrum sharing with ultra-dense in-building small cells in $5 \mathrm{G}$ era. In Proceedings of the 2019 IEEE 90th Vehicular Technology Conference (VTC2019-Fall), Honolulu, HI, USA, 22-25 September; pp. 1-7.

142. Zhang, H.; Chu, X.; Guo, W.; Wang, S. Coexistence of Wi-Fi and heterogeneous small cell networks sharing unlicensed spectrum. IEEE Commun. Mag. 2015, 53, 158-164. [CrossRef]

143. Song, J.; Choi, W. Minimum Cache Size and Backhaul Capacity for Cache-Enabled Small Cell Networks. IEEE Wirel. Commun. Lett. 2018. [CrossRef]

144. Akhtar, T.; Politis, I.; Tselios, C.; Kotsopoulos, S. Cooperative game radio resource management scheme for small cell network. In Proceedings of the 2019 IEEE 2nd 5G World Forum (5GWF), Dresden, Germany, 30 September-2 October 2019; pp. 69-73.

145. Maltsev, A.; Bolotin, I.; Pudeyev, A.; Morozov, G.; Davydov, A. Performance evaluation of the isolated mmWave small cell. In Proceedings of the 2015 IEEE 26th Annual International Symposium on Personal, Indoor, and Mobile Radio Communications (PIMRC), Hong Kong, China, 30 August-2 September 2015; pp. 2354-2358.

146. Chung, Y.-L. An energy-efficient coverage algorithm for macrocell—Small cell network systems. Energies 2017, 10, 1319. [CrossRef]

147. Mollahasani, S.; Onur, E. Density-aware, energy-and spectrum-efficient small cell scheduling. IEEE Access 2019, 7, 65852-65869. [CrossRef]

148. Wang, S.; Zhao, W.; Wang, C. Budgeted cell planning for cellular networks with small cells. IEEE Trans. Veh. Technol. 2015, 64, 4797-4806. [CrossRef]

149. Chung, K.-S.; Keum, C. Mobile data offloading service using file cloud in small cells. In Proceedings of the 2015 International Conference on Information and Communication Technology Convergence (ICTC), Jeju, Korea, 28-30 October 2015; pp. 936-938.

150. Klessig, H.; Ohmann, D.; Reppas, A.I.; Hatzikirou, H.; Abedi, M.; Simsek, M.; Fettweis, G.P. From Immune Cells to Self-Organizing Ultra-Dense Small Cell Networks. IEEE J. Sel. Areas Commun. 2016, 34, 800-811. [CrossRef]

151. Zhang, L.; Xiao, M.; Wu, G.; Alam, M.; Liang, Y.-C.; Li, S. A survey of advanced techniques for spectrum sharing in $5 \mathrm{G}$ networks. IEEE Wirel. Commun. 2017, 24, 44-51. [CrossRef]

152. Wan, L.; Guo, Z.; Chen, X. Enabling Efficient 5G NR and 4G LTE Coexistence. IEEE Wirel. Commun. 2019, 26, 6-8. [CrossRef]

153. Qamar, F.; Siddiqui, M.H.S.; Hindia, M.N.; Dimyati, K.; Rahman, T.A.; Talip, M.S.A. Propagation Channel Measurement at $38 \mathrm{GHz}$ for $5 \mathrm{G}$ mm-wave communication Network. In Proceedings of the 2018 IEEE Student Conference on Research and Development (SCOReD), Selangor, Malaysia, 26-28 November 2018; pp. 1-6.

154. Al-Falahy, N.; Alani, O.Y. Millimetre wave frequency band as a candidate spectrum for $5 \mathrm{G}$ network architecture: A survey. Phys. Commun. 2019, 32, 120-144. [CrossRef]

155. Tikhomirov, A.; Omelyanchuk, E.; Semenova, A. Recommended 5G frequency bands evaluation. In Proceedings of the 2018 Systems of Signals Generating and Processing in the Field of on Board Communications, Moscow, Russia, 14-15 March 2018; pp. 1-5.

156. Alam, T.; Thummaluru, S.R.; Chaudhary, R.K. Integration of MIMO and Cognitive Radio for Sub-6 GHz 5G Applications. IEEE Antennas Wirel. Propag. Lett. 2019, 18, 2021-2025. [CrossRef]

157. Carrasco, E.; Colombi, D.; Foster, K.R.; Ziskin, M.; Balzano, Q. Exposure assessment of portable wireless devices above 6 GHz. Radiat. Prot. Dosim. 2019, 183, 489-496. [CrossRef]

158. Deng, J.; Tirkkonen, O.; Freij-Hollanti, R.; Chen, T.; Nikaein, N. Resource allocation and interference management for opportunistic relaying in integrated mmWave/sub-6 GHz 5G networks. IEEE Commun. Mag. 2017, 55, 94-101. [CrossRef]

159. Feng, M.; Mao, S. Adaptive pilot design for massive MIMO HetNets with wireless backhaul. In Proceedings of the 2017 14th Annual IEEE International Conference on Sensing, Communication, and Networking (SECON), San Diego, CA, USA, 12-14 June 2017; pp. 1-9. 
160. Waidhuba, M.K.; Tiang, S.S.; Manzoor, S.; Hong, M.V. A Wireless Backhaul using a Massive MIMO-5G NR HetNet design; at Sub-6GHz and MillimetreWave Frequencies. In Proceedings of the 2019 7th International Conference on Smart Computing \& Communications (ICSCC), Sarawak, Malaysia, 28-30 June 2019; pp. 1-5.

161. Kurita, D.; Kitayama, D.; Miyachi, K.; Kishiyama, Y.; Itoh, S.; Murai, H.; Simonsson, A.; Okvist, P.; Fwu, J.-K.; Zhuang, X. Outdoor Experiments on 5G Radio Access in 5G Trial Site Using Core Network in 28-GHz Frequency Band. In Proceedings of the 2019 IEEE 90th Vehicular Technology Conference (VTC2019-Fall), Honolulu, HI, USA, 22-25 September; pp. 1-6.

162. Martinez-Ingles, M.-T.; Pascual-García, J.; Gaillot, D.P.; Borras, C.S.; Molina-García-Pardo, J.-M. Indoor 1-40 GHz channel measurements. In Proceedings of the 2019 13th European Conference on Antennas and Propagation (EuCAP), Krakow, Poland, 31 March-5 April 2019; pp. 1-5.

163. El Hajj, M.; Zaharia, G.; El Zein, G.; Farhat, H.; Sadek, S. Millimeter-wave propagation measurements at $60 \mathrm{GHz}$ in indoor environments. In Proceedings of the 2019 International Symposium on Signals, Circuits and Systems (ISSCS), Iasi, Romania, 11-12 July 2019; pp. 1-4.

164. Wang, T.; Li, G.; Huang, B.; Miao, Q.; Fang, J.; Li, P.; Tan, H.; Ding, J.; Li, J.; Wang, Y. Spectrum Analysis and Regulations for 5G. In 5G Mobile Communications; Xiang, W., Zheng, K., Shen, X., Eds.; Springer: Cham, Switzerland, 2017; pp. 27-50.

165. AT\&T. AT\&T Expanding Fixed Wireless 5G Trials to Additional Markets. 2017. Available online: https://about.att.com/story/att_expanding_fixed_wireless_5g_trials_to_additional_markets.html (accessed on 30 August 2017).

166. Hassan, N.; Fernando, X. Massive MIMO wireless networks: An overview. Electronics 2017, 6, 63. [CrossRef]

167. Khawaja, W.; Ozdemir, O.; Yapici, Y.; Erden, F.; Guvenc, I. Coverage enhancement for NLOS mmWave links using passive reflectors. IEEE Open J. Commun. Soc. 2020, 1, 263-281. [CrossRef]

168. Chuo, L.-X.; Luo, Z.; Sylvester, D.; Blaauw, D.; Kim, H.-S. Rf-echo: A non-line-of-sight indoor localization system using a low-power active rf reflector asic tag. In Proceedings of the 23rd Annual International Conference on Mobile Computing and Networking, Salt Lake City, UT, USA, 9-13 October 2017; pp. 222-234.

169. Tafintsev, N.; Moltchanov, D.; Gerasimenko, M.; Gapeyenko, M.; Zhu, J.; Yeh, S.-p.; Himayat, N.; Andreev, S.; Koucheryavy, Y.; Valkama, M. Aerial Access and Backhaul in mmWave B5G Systems: Performance Dynamics and Optimization. IEEE Commun. Mag. 2020, 58, 93-99. [CrossRef]

170. Chuenchom, R.; Zou, X.; Schrinski, N.; Babiel, S.; Hermelo, M.F.; Steeg, M.; Steffan, A.; Honecker, J.; Leiba, Y.; Stöhr, A. E-band 76-GHz coherent RoF backhaul link using an integrated photonic mixer. J. Lightwave Technol. 2016, 34, 4744-4750. [CrossRef]

171. Dutty, H.B.H.; Mowla, M.M.; Mou, M.A. Millimeter Wave Channel Modeling for Aviation Backhaul Networks in 5G communications. In Proceedings of the 2019 22nd International Conference on Computer and Information Technology (ICCIT), Dhaka, Bangladesh, 18-20 December 2019; pp. 1-5.

172. Kuo, P.-H.; Mourad, A. Millimeter wave for 5G mobile fronthaul and backhaul. In Proceedings of the 2017 European conference on networks and communications (EuCNC), Oulu, Finland, 12-15 June 2017; pp. 1-5.

173. Han, C.; Duan, S.; Bao, L.; Zhang, G.; Ji, B.; Ran, L. E-Band Link for Next Generation Small-Cell Backhaul in Dense Urban Environment. In Proceedings of the 2019 IEEE 90th Vehicular Technology Conference (VTC2019-Fall), Honolulu, HI, USA, 22-25 September; pp. 1-2.

174. Awais, M.; Khaliq, H.S.; Khan, W.T. A novel dual-band millimeter-wave antenna for automotive radar and multi-gigabit wireless communications. In Proceedings of the 2017 Progress in Electromagnetics Research Symposium-Fall (PIERS-FALL), Singapore, 19-22 November 2017; pp. 2802-2807.

175. MacCartney, G.R., Jr.; Sun, S.; Rappaport, T.S.; Xing, Y.; Yan, H.; Koka, J.; Wang, R.; Yu, D. Millimeter wave wireless communications: New results for rural connectivity. In Proceedings of the 5th Workshop on All Things Cellular: Operations, Applications and Challenges, London, UK, 18-21 August 2015; pp. 31-36.

176. Rappaport, T.S.; Xing, Y.; Kanhere, O.; Ju, S.; Madanayake, A.; Mandal, S.; Alkhateeb, A.; Trichopoulos, G.C. Wireless communications and applications above $100 \mathrm{GHz}$ : Opportunities and challenges for 6G and beyond. IEEE Access 2019, 7, 78729-78757. [CrossRef]

177. Q Qamar, F.; Siddiqui, M.H.S.; Dimyati, K.; Noordin, K.A.B.; Majed, M.B. Channel characterization of 28 and 38 GHz MM-wave frequency band spectrum for the future 5G network. In Proceedings of the 2017 IEEE 15th student conference on research and development (SCOReD), Putrajaya, Malaysia, 13-14 December 2017; pp. 291-296. 
178. Xing, Y.; Rappaport, T.S. Propagation measurement system and approach at $140 \mathrm{GHz}$-moving to 6G and above $100 \mathrm{GHz}$. In Proceedings of the 2018 IEEE Global Communications Conference (GLOBECOM), Abu Dhabi, UAE, 9-13 December 2018; pp. 1-6.

179. Sun, Q.; Chin-Lin, I.; Han, S.; Xu, Z.; Pan, Z. Software defined air interface: A framework of $5 \mathrm{G}$ air interface. In Proceedings of the IEEE Wireless Communications and Networking Conference Workshops (WCNCW), New Orleans, LA, USA, 9-12 March 2015; pp. 6-11.

180. Richter, L.; Hoyer, M.; Ilsen, S. A Software Defined Radio based FeMBMS Measurement Receiver: Test Results. In Proceedings of the 2019 IEEE International Symposium on Broadband Multimedia Systems and Broadcasting (BMSB), Jeju, Korea, 5-7 June 2019; pp. 1-9.

181. Alhasani, M.M.; Nguyen, Q.N.; Ohta, G.-I.; Sato, T. A Novel Four Single-Sideband M-QAM Modulation Scheme Using a Shadow Equalizer for MIMO System Toward 5G Communications. Sensors 2019, 19, 1944. [CrossRef] [PubMed]

182. Sawada, M.; Nguyen, Q.N.; Alhasani, M.M.; Sato, T. A Novel Analytical OFDM Modulation Framework using Wavelet Transform with Window Function in the Hilbert space. Procedia Comput. Sci. 2020, 171, 1303-1312. [CrossRef]

183. Yu, S.; Lee, J.W. Channel sounding for multi-user massive MIMO in distributed antenna system environment. Electronics 2019, 8, 36. [CrossRef]

184. Vook, F.W.; Ghosh, A.; Thomas, T.A. MIMO and beamforming solutions for 5G technology. In Proceedings of the 2014 IEEE MTT-S International Microwave Symposium (IMS2014), Tampa, FL, USA, 1-6 June 2014; pp. 1-4.

185. Parikh, J.; Basu, A. (2019) Millimeter Waves: Technological Component for Next-Generation Mobile Networks. In Cognitive Radio, Mobile Communications and Wireless Networks; Rehmani, M., Dhaou, R., Eds.; Springer: Cham, Switzerland, 2019; pp. 167-186.

186. Giordani, M.; Mezzavilla, M.; Zorzi, M. Initial access in 5G mmWave cellular networks. IEEE Commun. Mag. 2016, 54, 40-47. [CrossRef]

187. Rappaport, T.S.; Xing, Y.; MacCartney, G.R.; Molisch, A.F.; Mellios, E.; Zhang, J. Overview of millimeter wave communications for fifth-generation $(5 \mathrm{G})$ wireless networks-With a focus on propagation models. IEEE Trans. Antennas Propag. 2017, 65, 6213-6230. [CrossRef]

188. Hur, S.; Baek, S.; Kim, B.; Chang, Y.; Molisch, A.F.; Rappaport, T.S.; Haneda, K.; Park, J. Proposal on millimeter-wave channel modeling for 5G cellular system. IEEE J. Sel. Top. Signal Process. 2016, 10, 454-469. [CrossRef]

189. Qamar, F.; Hindia, M.N.; Abbas, T.; Dimyati, K.B.; Amiri, I.S. Investigation of QoS performance evaluation over 5G network for indoor environment at millimeter wave bands. Int. J. Electron. Telecommun. 2019, 65, 95-101.

190. Hindia, M.N.; Al-Samman, A.M.; Rahman, T.B.A. Investigation of large-scale propagation for outdoor-parking lot environment for 5G wireless communications. In Proceedings of the 2016 IEEE 3rd International Symposium on Telecommunication Technologies (ISTT), Kuala Lumpur, Malaysia, 28-30 November 2016; pp. 14-18.

191. Qamar, F.; Abbas, T.; Hindia, M.N.; Dimyati, K.B.; Noordin, K.A.B.; Ahmed, I. Characterization of MIMO propagation channel at $15 \mathrm{GHz}$ for the $5 \mathrm{G}$ spectrum. In Proceedings of the 2017 IEEE 13th Malaysia International Conference on Communications (MICC), Johor Bahru, Malaysia, 28-30 November 2017; pp. 265-270.

192. Samimi, M.K.; Rappaport, T.S.; MacCartney, G.R. Probabilistic omnidirectional path loss models for millimeter-wave outdoor communications. IEEE Wirel. Commun. Lett. 2015, 4, 357-360. [CrossRef]

193. Abbas, T.; Qamar, F.; Ahmed, I.; Dimyati, K.; Majed, M.B. Propagation channel characterization for 28 and $73 \mathrm{GHz}$ millimeter-wave 5G frequency band. In Proceedings of the 2017 IEEE 15th Student Conference on Research and Development (SCOReD), Putrajaya, Malaysia, 13-14 December 2017; pp. 297-302.

194. Al-Samman, A.; Hindia, M.; Rahman, T. Path loss model in outdoor environment at $32 \mathrm{GHz}$ for $5 \mathrm{G}$ system. In Proceedings of the 2016 IEEE 3rd International Symposium on Telecommunication Technologies (ISTT), Kuala Lumpur, Malaysia, 28-30 November 2016; pp. 9-13.

195. Rappaport, T.S.; MacCartney, G.R.; Samimi, M.K.; Sun, S. Wideband millimeter-wave propagation measurements and channel models for future wireless communication system design. IEEE Trans. Commun. 2015, 63, 3029-3056. [CrossRef] 
196. MacCartney, G.R., Jr.; Deng, S.; Rappaport, T.S. Indoor office plan environment and layout-based mmWave path loss models for $28 \mathrm{GHz}$ and $73 \mathrm{GHz}$. In Proceedings of the 2016 IEEE 83rd Vehicular Technology Conference (VTC Spring), Nanjing, China, 15-18 May 2016.

197. Yildirim, F.; Sadri, A.S.; Liu, H. Polarization effects for indoor wireless communications at $60 \mathrm{GHz}$. IEEE Commun. Lett. 2008, 12, 660-662. [CrossRef]

198. Deng, S.; Samimi, M.K.; Rappaport, T.S. $28 \mathrm{GHz}$ and $73 \mathrm{GHz}$ millimeter-wave indoor propagation measurements and path loss models. In Proceedings of the 2015 IEEE International Conference on Communication Workshop (ICCW), London, UK, 8-12 June 2015; pp. 1244-1250.

199. AlAbdullah, A.A.; Ali, N.; Obeidat, H.; Abd-Alhmeed, R.A.; Jones, S. Indoor millimetre-wave propagation channel simulations at 28,39,60 and $73 \mathrm{GHz}$ for $5 \mathrm{G}$ wireless networks. In Proceedings of the Internet Technologies and Applications (ITA), Wrexham, UK, 12-15 September 2017; pp. 235-239.

200. Khasdev, B.; Hirwe, A. Overview of MIMO Technology in LTE, LTE-A \& LTE-A-Pro. Int. J. Eng. Comput. Sci. 2016, 5, 19227-19229.

201. Maruta, K.; Falcone, F. Massive MIMO Systems: Present and Future. Electronics 2020, 9, 385. [CrossRef]

202. Al-Hussaibi, W.A.; Ali, F.H. Group layer MU-MIMO for 5G wireless systems. Telecommun. Syst. 2019, 70, 525-540. [CrossRef]

203. Larsson, E.G.; Van der Perre, L. Massive MIMO for 5G. IEEE 5G Tech. Focus. 2017, 1, Number 1. Available online: https://futurenetworks.ieee.org/tech-focus/march-2017/massive-mimo-for-5g (accessed on 26 August 2020).

204. Abdullah, N.F.; Nordin, R.; Doufexi, A.; Nix, A.R. Effect of beamforming on mmWave Systems in various Realistic Environments. In Proceedings of the 2017 IEEE 85th Vehicular Technology Conference (VTC Spring), Sydney, Australia, 4-7 June 2017; pp. 1-5.

205. Nusenu, S.Y.; Asare, E. Butler Matrix Frequency Diverse Retrodirective Array Beamforming: An Energy-Efficient Technique for mmWave Networks. Wirel. Commun. Mob. Comput. 2020. [CrossRef]

206. Bhandari, R.; Jadhav, S. Novel spectral efficient technique for MIMO-OFDM channel estimation with reference to PAPR and BER analysis. Wirel. Pers. Commun. 2019, 104, 1227-1242. [CrossRef]

207. Do, T.N.; Haas, Z.J. On the Design of RD-MIMO: Spatial Multiplexing Versus Opportunistic Transmission Schemes. IEEE Access 2020, 8, 22733-22747. [CrossRef]

208. Wang, J.; Jin, A.; Shi, D.; Wang, L.; Hu, L.; Gu, L.; Benjebbour, A. Field trials on spectral efficiency improvement in Massive MIMO systems. In Proceedings of the 2018 IEEE 87th Vehicular Technology Conference (VTC Spring), Porto, Portugal, 3-6 June 2018; pp. 1-5.

209. Marzetta, T.L. Fundamentals of Massive MIMO; Cambridge University Press: Cambridge, UK, 2016.

210. Gao, X.; Dai, L.; Han, S.; Chih-Lin, I.; Wang, X. Reliable beamspace channel estimation for millimeter-wave massive MIMO systems with lens antenna array. IEEE Trans. Wirel. Commun. 2017, 16, 6010-6021. [CrossRef]

211. Bjornson, E.; Van der Perre, L.; Buzzi, S.; Larsson, E.G. Massive MIMO in sub-6 GHz and mmWave: Physical, practical, and use-case differences. IEEE Wirel. Commun. 2019, 26, 100-108. [CrossRef]

212. Jan, M.A.; Hassan, S.A.; Jung, H. QoS-based Performance Analysis of mmWave UAV-assisted 5G Hybrid Heterogeneous Network. In Proceedings of the 2019 IEEE Global Communications Conference (GLOBECOM), Waikoloa, HI, USA, 9-13 December 2019; pp. 1-6.

213. Li, Y.-N.R.; Gao, B.; Zhang, X.; Huang, K. Beam Management in Millimeter-Wave Communications for 5G and Beyond. IEEE Access 2020, 8, 13282-13293. [CrossRef]

214. Sanguinetti, L.; Björnson, E.; Hoydis, J. Toward massive MIMO 2.0: Understanding spatial correlation, interference suppression, and pilot contamination. IEEE Trans. Commun. 2019, 68, 232-257. [CrossRef]

215. Arnold, M.; Wang, X.; Ten Brink, S. Subcarrier-interlaced FDD for faster-than-TDD channel tracking in massive MIMO systems. In Proceedings of the WSA 2018; 22nd International ITG Workshop on Smart Antennas, Bochum, Germany, 14-16 March 2018; pp. 1-7.

216. Americas, G. Advanced Antenna Systems for 5G. White Paper. 2019. Available online: https://www.5gamericas. org/wp-content/uploads/2019/08/5G-Americas_Advanced-Antenna-Systems-for-5G-White-Paper.pdf (accessed on 15 August 2019).

217. Suárez, L.; Sherstobitov, A.; Lyashev, V. Reduced Redundancy Indexing for Beam-Time Delay CSI Compression in 5G FDD Massive MIMO Systems. In Proceedings of the 2019 IEEE International Black Sea Conference on Communications and Networking (BlackSeaCom), Sochi, Russia, 3-6 June 2019; pp. 1-5. 
218. Matalatala, M.; Deruyck, M.; Shikhantsov, S.; Tanghe, E.; Plets, D.; Goudos, S.; Psannis, K.E.; Martens, L.; Joseph, W. Multi-objective optimization of massive mimo $5 \mathrm{G}$ wireless networks towards power consumption, uplink and downlink exposure. Appl. Sci. 2019, 9, 4974. [CrossRef]

219. Arnold, M.; Dörner, S.; Cammerer, S.; Yan, S.; Hoydis, J.; Brink, S.t. Enabling FDD massive MIMO through deep learning-based channel prediction. arXiv 2019, arXiv:1901.03664.

220. Fang, J.; Li, X.; Li, H.; Gao, F. Low-rank covariance-assisted downlink training and channel estimation for FDD massive MIMO systems. IEEE Trans. Wirel. Commun. 2017, 16, 1935-1947. [CrossRef]

221. Peters, G.M. Time Division Duplex (TDD) Multi-User Multiple-Input, Multiple-Output (MU-MIMO) Mobile Ad-Hoc Network (MANET). Master's Thesis, University of Cincinnati, Cincinnati, OH, USA, 2019.

222. Saito, Y.; Benjebbour, A.; Kishiyama, Y.; Wang, X.; Hou, X.; Jiang, H.; Lu, L.; Liang, W.; Li, B.; Gu, L. Large scale field experimental trial of downlink TDD Massive MIMO at the $4.5 \mathrm{GHz}$ band. In Proceedings of the 2017 IEEE 85th Vehicular Technology Conference (VTC Spring), Sydney, Australia, 4-7 June 2017; pp. 1-5.

223. Wang, X.; Hou, X.; Jiang, H.; Benjebbour, A.; Saito, Y.; Kishiyama, Y.; Qiu, J.; Shen, H.; Tang, C.; Tian, T. Large scale experimental trial of 5G mobile communication systems-TDD massive MIMO with linear and non-linear precoding schemes. In Proceedings of the 2016 IEEE 27th Annual International Symposium on Personal, Indoor, and Mobile Radio Communications (PIMRC), Valencia, Spain, 4-8 September 2016; pp. 1-5.

224. Okuyama, T.; Suyama, S.; Mashino, J.; Okumura, Y.; Izui, K.; Yamazaki, K. 5G experimental trials of 4.5 GHz band digital beamforming in dense urban area. In Proceedings of the 2018 IEEE 29th Annual International Symposium on Personal, Indoor and Mobile Radio Communications (PIMRC), Bologna, Italy, 9-12 September 2018; pp. 1130-1131.

225. Um, J.; Park, J.; Park, S. Multi-antenna-based transmission strategy in 5 GHz unlicensed band. In Proceedings of the 2016 Eighth International Conference on Ubiquitous and Future Networks (ICUFN), Vienna, Austria, 5-8 July 2016; pp. 651-655.

226. Dahlman, E.; Parkvall, S.; Skold, J. 4G, LTE-Advanced Pro and the Road to 5G; Academic Press: Cambridge, MA, USA, 2016.

227. Chataut, R.; Akl, R. Efficient and low complex uplink detection for $5 \mathrm{G}$ massive MIMO systems. In Proceedings of the 2018 IEEE 19th Wireless and Microwave Technology Conference (WAMICON), Sand Key, FL, USA, 9-10 April 2018; pp. 1-6.

228. Pappa, M.; Ramesh, C.; Kumar, M.N. Performance comparison of massive MIMO and conventional MIMO using channel parameters. In Proceedings of the 2017 International Conference on Wireless Communications, Signal Processing and Networking (WiSPNET), Chennai, India, 22-24 March 2017; pp. 1808-1812.

229. Garcia, N.; Wymeersch, H.; Larsson, E.G.; Haimovich, A.M.; Coulon, M. Direct localization for massive MIMO. IEEE Trans. Signal Process. 2017, 65, 2475-2487. [CrossRef]

230. Rithe, J.P.; Khairnar, D.; Sharma, M. Performance of cooperative massive MIMO 5G cellular system. In Proceedings of the 2017 International Conference on Information, Communication, Instrumentation and Control (ICICIC), Indore, India, 17-19 August 2017; pp. 1-5.

231. Kashima, T.; Qiu, J.; Shen, H.; Tang, C.; Tian, T.; Wang, X.; Hou, X.; Jiang, H.; Benjebbour, A.; Saito, Y. Large scale massive MIMO field trial for 5G mobile communications system. In Proceedings of the 2016 International Symposium on Antennas and Propagation (ISAP), Okinawa, Japan, 24-28 October 2016; pp. 602-603.

232. Dikmen, O.; Kulac, S. A New Method in Pilot Reuse Factor Selection in Spectrum Efficient Massive MIMO Systems. Elektron. Elektrotechnika 2019, 25, 70-77. [CrossRef]

233. Gao, X.; Edfors, O.; Rusek, F.; Tufvesson, F. Massive MIMO Performance Evaluation Based on Measured Propagation Data. IEEE Trans. Wirel. Commun. 2015, 14, 3899-3911. [CrossRef]

234. Mahyiddin, W.A.; Martin, P.A.; Smith, P.J. Massive MIMO Systems in Time-Selective Channels. IEEE Commun. Lett. 2015, 19, 1973-1976. [CrossRef]

235. Fang, X.; Fang, S.; Ying, N.; Cao, H.; Liu, C. The performance of massive MIMO systems under correlated channel. In Proceedings of the 2013 19th IEEE International Conference on Networks (ICON), Singapore, 11-13 December 2013; pp. 1-4.

236. Chataut, R.; Akl, R. Channel Gain Based User Scheduling for 5G Massive MIMO Systems. In Proceedings of the 2019 IEEE 16th International Conference on Smart Cities: Improving Quality of Life Using ICT \& IoT and AI (HONET-ICT), Charlotte, NC, USA, 6-9 October 2019; pp. 49-53. 
237. Shajaiah, H.; Abdelhadi, A.; Clancy, C. Resource Allocation with Carrier Aggregation for Commercial Use of $3.5 \mathrm{GHz}$ Spectrum. In Resource Allocation with Carrier Aggregation in Cellular Networks; Springer: Cham, Switzerland, 2019; pp. 133-151. [CrossRef]

238. Kiwoli, L.; Sam, A.; Manasseh, E. Performance analysis of carrier aggregation for various mobile network implementations scenario based on spectrum allocated. arXiv 2017, arXiv:1711.02287.

239. Cao, Y.; Sunde, E.J.; Chen, K. Multiplying Channel Capacity: Aggregation of Fragmented Spectral Resources. IEEE Microw. Mag. 2019, 20, 70-77. [CrossRef]

240. Malladi, D.P.; Bhushan, N.; Luo, T.; Wei, Y. LTE/LTE-A Uplink Carrier Aggregation Using Unlicensed Spectrum. U.S. Patent 9,883,404, 30 January 2018.

241. Vu, L.H.; Yun, J.-H. Adaptive Self-Deferral for Carrier Aggregation of LTE-LAA With RF Power Leakage in Unlicensed Spectrum. IEEE Access 2019, 7, 89292-89305. [CrossRef]

242. Challita, U.; Dong, L.; Saad, W. Deep learning for proactive resource allocation in LTE-U networks. In Proceedings of the European wireless technology conference, Dresden, Germany, 17-19 May 2017.

243. Belikaidis, I.-P.; Georgakopoulos, A.; Demestichas, P.; Miscopein, B.; Filo, M.; Vahid, S.; Okyere, B.; Fitch, M. Multi-RAT dynamic spectrum access for 5G heterogeneous networks: The SPEED-5G approach. IEEE Wirel. Commun. 2017, 24, 14-22. [CrossRef]

244. Ferreira, M.V.G.; Vieira, F.H.T.; Felix, J.P.; de Souza, D.F.; Franco, R.A.P. Application of Evolutionary Algorithm to Allocate Resources in Wireless Networks with Carrier Aggregation. In Proceedings of the 2018 IEEE Congress on Evolutionary Computation (CEC), Rio de Janeiro, Brazil, 8-13 July 2018; pp. 1-8.

245. John, M.S.; Soumya, J. Achieving Cognitive Radio for Improved Spectrum Utilization: An Implementation. Int. Res. J. Eng. Technol. 2019, 6, 4882-4885.

246. Ivanov, A. Feature Extraction in Local Spectrum Sensing for Next Generation Cognitive Radios-A Review. J. Mob. Multimed. 2019, 15, 111-140. [CrossRef]

247. Gupta, A.; Majumder, S. Cognitive Radio Spectrum Classification using FLA-SVM. In Proceedings of the 2019 9th Annual Information Technology, Electromechanical Engineering and Microelectronics Conference (IEMECON), Jaipur, India, 13-15 March 2019; pp. 144-149.

248. Kakalou, I.; Papadopoulou, D.; Xifilidis, T.; Psannis, K.E.; Siakavara, K.; Ishibashi, Y. A survey on spectrum sensing algorithms for cognitive radio networks. In Proceedings of the 2018 7th International Conference on Modern Circuits and Systems Technologies (MOCAST), Thessaloniki, Greece, 7-9 May 2018; pp. 1-4.

249. Cherian, S.; Shiras, S. Spectrum sensing of SC-FDMA signals in cognitive radio networks. In Proceedings of the 2017 International Conference on Networks \& Advances in Computational Technologies (NetACT), Thiruvanthapuram, India, 20-22 July 2017; pp. 15-18.

250. Arjoune, Y.; Kaabouch, N. A comprehensive survey on spectrum sensing in cognitive radio networks: Recent advances, new challenges, and future research directions. Sensors 2019, 19, 126. [CrossRef] [PubMed]

251. Elhachmi, J.; Guennoun, Z. Cognitive radio spectrum allocation using genetic algorithm. EURASIP J. Wirel. Commun. Netw. 2016, 2016, 133. [CrossRef]

252. Zhou, X.; Sun, M.; Li, G.Y.; Juang, B.-H.F. Intelligent wireless communications enabled by cognitive radio and machine learning. China Commun. 2018, 15, 16-48.

253. Anandakumar, H.; Umamaheswari, K. Supervised machine learning techniques in cognitive radio networks during cooperative spectrum handovers. Clust. Comput. 2017, 20, 1505-1515. [CrossRef]

254. Ganesh Babu, R.; Amudha, V. A Survey on Artificial Intelligence Techniques in Cognitive Radio Networks. In Emerging Technologies in Data Mining and Information Security; Abraham, A., Dutta, P., Mandal, J., Bhattacharya, A., Dutta, S., Eds.; Springer: Singapore, 2019; pp. 99-110.

255. Wang, D.; Song, B.; Chen, D.; Du, X. Intelligent cognitive radio in 5G: AI-based hierarchical cognitive cellular networks. IEEE Wirel. Commun. 2019, 26, 54-61. [CrossRef]

256. Ghosh, A. 5G Small Cell Technology. Available online: https://www.picasso-project.eu/wp-content/uploads/ 2017/06/2017-06-19-10h50_5G_Gosh.pdf (accessed on 19 June 2017).

257. Alsheyab, H.Y.; Choudhury, S.; Bedeer, E.; Ikki, S.S. Near-Optimal Resource Allocation Algorithms for 5G+ Cellular Networks. IEEE Trans. Veh. Technol. 2019, 68, 6578-6592. [CrossRef]

258. Zhao, F.; Tang, Q. A KNN learning algorithm for collusion-resistant spectrum auction in small cell networks. IEEE Access 2018, 6, 45796-45803. [CrossRef]

259. Chen, H.; Zhao, D.; Chen, Q.; Chai, R. Joint Computation Offloading and Radio Resource Allocations in Small-Cell Wireless Cellular Networks. IEEE Trans. Green Commun. Netw. 2020. [CrossRef] 
260. Simon, M.; Kofi, E.; Libin, L.; Aitken, M. ATSC 3.0 Broadcast 5G Unicast Heterogeneous Network Converged Services Starting Release 16. IEEE Trans. Broadcast. 2020. [CrossRef]

261. Farokhi, M.; Zolghadrasli, A. Dynamic Spectrum, Subcarrier and Power Allocation in Heterogeneous Cellular Networks Based on Interference and Small Cells' Backhaul Limitations. Arab. J. Sci. Eng. 2017, 42, 2685-2696. [CrossRef]

262. Zubair, S.; Jangsher, S.; Mao, Y.; Li, V.O. Blockage-Aware Power Allocation and Relay Selection in Millimeter-Wave Small Cell Network. In Proceedings of the 2019 16th IEEE Annual Consumer Communications \& Networking Conference (CCNC), Las Vegas, NV, USA, 11-14 January 2019; pp. 1-5.

263. Wang, Y.T.; Cai, Y.Z.; Chen, L.A.; Lin, S.J.; Tsai, M.H. Backhaul-Based Cooperative Caching in Small Cell Network. In International Conference on Advanced Information Networking and Applications; Barolli, L., Takizawa, M., Xhafa, F., Enokido, T., Eds.; Springer: Cham, Switzerland, 2020; pp. 725-736.

264. Lei, L.; Yuan, Y.; Vu, T.X.; Chatzinotas, S.; Ottersten, B. Learning-based resource allocation: Efficient content delivery enabled by convolutional neural network. In Proceedings of the 2019 IEEE 20th International Workshop on Signal Processing Advances in Wireless Communications (SPAWC), Cannes, France, 2-5 July 2019; pp. 1-5.

265. Wang, L.; Yang, C.; Hu, R.Q. Autonomous traffic offloading in heterogeneous ultra-dense networks using machine learning. IEEE Wirel. Commun. 2019, 26, 102-109. [CrossRef]

266. SelvaKumar, N.; Rohini, M.; Narmada, C.; Yogeshprabhu, M. Network Traffic Control Using AI. Int. J. Sci. Res. Netw. Secur. Commun. 2020, 8, 13-21.

267. Wang, L.-C.; Cheng, S.-H. Data-driven resource management for ultra-dense small cells: An affinity propagation clustering approach. IEEE Trans. Netw. Sci. Eng. 2018, 6, 267-279. [CrossRef]

268. Li, Y.; Pateromichelakis, E.; Vucic, N.; Luo, J.; Xu, W.; Caire, G. Radio resource management considerations for $5 \mathrm{G}$ millimeter wave backhaul and access networks. IEEE Commun. Mag. 2017, 55, 86-92. [CrossRef]

269. Rebato, M.; Park, J.; Popovski, P.; De Carvalho, E.; Zorzi, M. Stochastic geometric coverage analysis in mmWave cellular networks with a realistic channel model. In Proceedings of the GLOBECOM 2017-2017 IEEE Global Communications Conference, Singapore, 4-8 December 2017; pp. 1-6.

270. Rebato, M.; Park, J.; Popovski, P.; De Carvalho, E.; Zorzi, M. Stochastic geometric coverage analysis in mmWave cellular networks with realistic channel and antenna radiation models. IEEE Trans. Commun. 2019, 67, 3736-3752. [CrossRef]

271. Khawaja, W.A.G.; Ozdemir, O.; Erden, F.; Guvenc, I.; Ezuma, M.; Kakishima, Y. Effect of passive reflectors for enhancing coverage of $28 \mathrm{GHz}$ mmWave systems in an outdoor setting. In Proceedings of the 2019 IEEE Radio and Wireless Symposium (RWS), Orlando, FL, USA, 20-23 January 2019; pp. 1-4.

272. Shi, M.; Yang, K.; Han, Z.; Niyato, D. Coverage analysis of integrated sub-6GHz-mmWave cellular networks with hotspots. IEEE Trans. Commun. 2019, 67, 8151-8164. [CrossRef]

273. Pometcu, L.; D'Errico, R. Channel Model Characteristics in D-Band for NLOS Indoor Scenarios. In Proceedings of the 2019 13th European Conference on Antennas and Propagation (EuCAP), Krakow, Poland, 31 March-5 April 2019; pp. 1-4.

274. Geng, C.; Yuan, X.; Huang, H. Exploiting channel correlations for NLOS ToA localization with multivariate Gaussian mixture models. IEEE Wirel. Commun. Lett. 2019, 9, 70-73. [CrossRef]

275. Sun, S.; Rappaport, T.S.; Shafi, M.; Tang, P.; Zhang, J.; Smith, P.J. Propagation models and performance evaluation for $5 \mathrm{G}$ millimeter-wave bands. IEEE Trans. Veh. Technol. 2018, 67, 8422-8439. [CrossRef]

276. Antonescu, B.; Tehrani Moayyed, M.; Basagni, S. Clustering Algorithms and Validation Indices for a Wide mmWave Spectrum. Information 2019, 10, 287. [CrossRef]

277. Talvitie, J.; Koivisto, M.; Levanen, T.; Valkama, M.; Destino, G.; Wymeersch, H. High-Accuracy Joint Position and Orientation Estimation in Sparse 5G mmWave Channel. In Proceedings of the ICC 2019-2019 IEEE International Conference on Communications (ICC), Shanghai, China, 20-24 May 2019; pp. 1-7.

278. Qamar, F.; Hindia, M.; Dimyati, K.; Noordin, K.A.; Majed, M.B.; Abd Rahman, T.; Amiri, I.S. Investigation of future $5 \mathrm{G}-\mathrm{IoT}$ millimeter-wave network performance at $38 \mathrm{GHz}$ for urban microcell outdoor environment. Electronics 2019, 8, 495. [CrossRef]

279. Amiri, R.; Mehrpouyan, H. Self-organizing mm wave networks: A power allocation scheme based on machine learning. In Proceedings of the 2018 11th Global Symposium on Millimeter Waves (GSMM), Boulder, CO, USA, 22-24 May 2018; pp. 1-4. 
280. Antón-Haro, C.; Mestre, X. Learning and data-driven beam selection for mmWave communications: An angle of arrival-based approach. IEEE Access 2019, 7, 20404-20415. [CrossRef]

281. Liao, S.; Ou, L. High-speed Millimeter-wave 5G/6G Image Transmission via Artificial Intelligence. arXiv 2020, arXiv:2007.03153.

282. Wu, Z.; Wu, B.; Su, Z.; Zhang, X. Development challenges for $5 \mathrm{G}$ base station antennas. In Proceedings of the 2018 International Workshop on Antenna Technology (iWAT), Nanjing, China, 5-7 March 2018; pp. 1-3.

283. Björnson, E.; Sanguinetti, L. Scalable cell-free massive MIMO systems. IEEE Trans. Commun. 2020. [CrossRef]

284. Arnold, M.; Hoydis, J.; ten Brink, S. Novel massive MIMO channel sounding data applied to deep learning-based indoor positioning. In Proceedings of the SCC 2019, 12th International ITG Conference on Systems, Communications and Coding, Rostock, Germany, 11-14 February 2019; pp. 1-6.

285. Shaheenbanu, M.; Suma, M. Investigation on Hybrid Precoding for Multi-user MIMO Systems. In Proceedings of the 2019 IEEE International WIE Conference on Electrical and Computer Engineering (WIECON-ECE), Bangalore, India, 15-16 November 2019; pp. 1-4.

286. Chung, M.; Liu, L.; Edfors, O.; Tufvesson, F. Demo: Millimeter-Wave Massive MIMO Testbed with Hybrid Beamforming. In Proceedings of the 2020 IEEE Wireless Communications and Networking Conference Workshops (WCNCW), Seoul, Korea, 6-9 April 2020; pp. 1-2.

287. Zhu, J.; Wang, Z.; Li, Q.; Chen, H.; Ansari, N. Mitigating Intended Jamming in mmWave MIMO by Hybrid Beamforming. IEEE Wirel. Commun. Lett. 2019, 8, 1617-1620. [CrossRef]

288. Taghikhani, P.; Buisman, K.; Fager, C. Hybrid Beamforming Transmitter Modeling for Millimeter-Wave MIMO Applications. IEEE Trans. Microw. Theory Tech. 2020. [CrossRef]

289. Okoth, P.J.; Nguyen, Q.N.; Dhakal, D.R.; Nozaki, D.; Yamada, Y.; Sato, T. An Efficient Codebook-Based Beam Training Technique for Millimeter-Wave Communication Systems. In Proceedings of the 2018 Asia-Pacific Microwave Conference (APMC), Kyoto, Japan, 6-9 November 2018; pp. 666-668.

290. Liu, Z.; Chen, Y.; Yang, M.; Jian, R. Hybrid Precoding Based on MMSE-EDS for Multi-user Multi-stream Massive MIMO Systems. In Proceedings of the 2019 28th Wireless and Optical Communications Conference (WOCC), Beijing, China, 9-10 May 2019; pp. 1-5.

291. Cui, M.; Zou, W.; Wang, Y.; Zhang, R. Low complexity joint hybrid precoding algorithm for millimeter wave MIMO systems. IEEE Access 2018, 6, 56423-56432. [CrossRef]

292. Bai, L.; Wang, C.-X.; Huang, J.; Xu, Q.; Yang, Y.; Goussetis, G.; Sun, J.; Zhang, W. Predicting wireless mmWave massive MIMO channel characteristics using machine learning algorithms. Wirel. Commun. Mob. Comput. 2018. [CrossRef]

293. Zhang, Y.; Alrabeiah, M.; Alkhateeb, A. Learning beam codebooks with neural networks: Towards environment-aware mmWave MIMO. arXiv 2020, arXiv:2002.10663.

294. Guan, M.; Wu, Z.; Cui, Y.; Cao, X.; Wang, L.; Ye, J.; Peng, B. Efficiency Evaluations Based on Artificial Intelligence for 5G Massive MIMO Communication Systems on High-Altitude Platform Stations. IEEE Trans. Ind. Inform. 2019, 16, 6632-6640. [CrossRef]

295. Vijay, A.; Umadevi, K. Explainable AI controlled architecture of D2D system for massive MIMO based 5G networks. Int. J. Sci. Res. Rev. 2019, 7, 33-40.

(C) 2020 by the authors. Licensee MDPI, Basel, Switzerland. This article is an open access article distributed under the terms and conditions of the Creative Commons Attribution (CC BY) license (http://creativecommons.org/licenses/by/4.0/). 